\title{
Current and emerging treatments for amyotrophic lateral sclerosis
}

This article was published in the following Dove Press journal:

Neuropsychiatric Disease and Treatment

2 November 2009

Number of times this article has been viewed

\author{
Stefano Zoccolella' \\ Andrea Santamato ${ }^{2}$ \\ Paolo Lamberti ${ }^{3}$ \\ 'Azienda Ospedaliero-Universitaria \\ Ospedali Riuniti, Department \\ of Medical and Neurological \\ Sciences, Clinic of Nervous System \\ Diseases, University of Foggia, Italy; \\ ${ }^{2}$ Department of Physical Medicine \\ and Rehabilitation, University \\ of Foggia, OORR, Italy; ${ }^{3}$ Department \\ of Neurology and Psychiatry, \\ University of Bari, Italy
}

Background: Amyotrophic lateral sclerosis (ALS) is a relatively rare neurodegenerative disorder of both upper and lower motoneurons. Currently, the management of ALS is essentially symptoms-based, and riluzole, an antiglutamatergic agent, is the only drug for the treatment of ALS approved by the food and drug administration.

Objective: We reviewed current literature concerning emerging treatments for amyotrophic lateral sclerosis.

Methods: A Medline literature search was performed to identify all studies on ALS treatment published from January 1st, 1986 through August 31st, 2009. We selected papers concerning only disease-modifying therapy.

Results: Forty-eight compounds were identified and reviewed in this study.

Conclusions: Riluzole is the only compound that demonstrated a beneficial effect on ALS patients, but with only modest increase in survival. Although several drugs showed effective results in the animal models for ALS, none of them significantly prolonged survival or improved quality of life of ALS patients. Several factors have been implicated in explaining the predominantly negative results of numerous randomized clinical trials in ALS, including methodological problems in the use of animal-drug screening, the lack of assessment of pharmacokinetic profile of the drugs, and methodological pitfalls of clinical trials in ALS patients.

Keywords: amyotrophic lateral sclerosis, therapy, drug, survival

\section{Introduction}

Amyotrophic lateral sclerosis (ALS) is a relatively rare neurodegenerative disorder characterized by progressive loss of both upper and lower motor neurons in the brain, brainstem, and spinal cord. The progression of the disease is usually rapid, leading to death on average within 3-5 years. ${ }^{1}$

The underlying cause of ALS remains unclear, but an interplay between endogenous (genetic, metabolic) and exogenous factors (environmental, lifestyle) is believed to be involved in the development of the disease. ${ }^{2,3}$

Although ALS usually develops sporadically, 5\%-10\% of cases are familial and hereditary. Twenty percent of familial ALS are caused by the mutation in $\mathrm{Cu} / \mathrm{Zn}$ superoxide dismutase-1 (SOD1) gene. ${ }^{1}$

The development of animal models of ALS has provided progress in understanding the underlying mechanisms of the disease because the sporadic and the familiar forms of ALS share similar clinical and pathological features. ${ }^{3,4}$

Several animal models have been extensively used in ALS through the years, including different transgenic mouse models, wobbler mouse and one canine model..$^{3,4}$
Correspondence: Stefano Zoccolella Azienda Ospedaliero-Universitaria Ospedali Riuniti, University of Foggia, Viale Pinto I, 7I 100 Foggia, Italy Tel +390881732553

$\mathrm{Fax}+390881736080$

Email stefzoc@hotmail.it 
The most clinically relevant animal model of ALS is the SOD1 transgenic rodent (mainly mice) model, that is genetically engineered to express a mutant form of the human SOD1 gene. The most commonly used SOD1 mouse harbors the glycine to alanine mutation at position 93 (G93A). This mutation results in a toxic gain of function of $\mathrm{Cu} / \mathrm{Zn}$ SOD1 that enhances the generation of damaging oxygen radicals. $^{3}$

A wide range of mechanisms are thought to be implicated in the pathogenesis of the disease: these include mitochondrial dysfunction, excitotoxicity, oxidative stress, protein misfolding, proteosomal dysfunction, aberrant growth factor signaling, microinflammatory process and glial activation. ${ }^{2-5}$

Riluzole, an antiglutamatergic agent that inhibits the presynaptic release of glutamate, is the only drug for the treatment of ALS approved by the US Food and Drug Administration (FDA). ${ }^{6}$ However, it is known to have limited therapeutic benefits and only modest effects on survival of ALS patients. ${ }^{6}$ Therefore, to date there is no effective cure for ALS and the management of ALS in clinical practice remains essentially supportive and symptoms-based.,

In recent years, great efforts have been made in the search for effective treatments of ALS; a large number of neuroprotective agents have been proposed candidates for the treatment of ALS and several clinical trials have been planned and conducted. ${ }^{8}$ The purpose of this review is to summarize the current and emerging treatments for amyotrophic lateral sclerosis.

\section{Methods}

A Medline literature search was performed to identify all studies on neuroprotective treatment of ALS published from January 1st, 1986 through August 31st, 2009, using the MeSH terms "motor neuron disease", "motor neurons", "amyotrophic lateral sclerosis", "treatment", "therapy", "clinical trials", "experimental studies", and "drugs". Articles and abstracts were included only when published in English. Additional references were taken from article citations. For the purpose of this review we considered only diseasemodifying therapy.

\section{Results}

Following data extraction, we identified a group of 48 potential therapeutic agents. These compounds were grouped and reviewed based on their hypothetical mechanisms of action (Table 1). A list of undergoing clinical trials for ALS is also reported (Table 2 ).

\section{Antiglutamate agents}

\section{Riluzole}

Riluzole is an antiglutamatergic agent thought to inhibit the presynaptic release of glutamate. ${ }^{9}$ In a mouse model of ALS, treatment with riluzole significantly delayed the onset of the disease and slowed the decline in motor function. ${ }^{8,9}$ Recently, a systematic review of ALS treatment with riluzole has been performed by the Cochrane Neuromuscular Diseases group. ${ }^{6}$ The review included four clinical trials (overall number of treated patients: 1,477$).{ }^{6}$ Based on this meta-analysis, riluzole treatment with $100 \mathrm{mg}$ daily was considered safe, well tolerated and was associated with a statistically significant improvement in tracheostomy-free survival. The effect size was however small, as the median increase in survival is about two to three months. ${ }^{6}$

Results from population-based studies indicated that riluzole therapy increased survival rates at 12 months by approximately $10 \%$ and prolonged survival by $4-6$ months. ${ }^{10,11}$ One study observed also a stronger beneficial effect amongst bulbar-onset ALS and patients aged $>70$ years (increase in median survival time: eight months). ${ }^{11}$ The favorable effect of the drug was transient and lost in prolonged follow-up (after 18 months). ${ }^{10,11}$ A study on transgenic rats demonstrated that the deficit in glutamate uptake becomes more severe by end-stage of the disease and is probably the cause for the loss of efficacy of the drug in advanced ALS. ${ }^{12}$ More studies are therefore needed, especially to clarify the effects of riluzole in older patients, in bulbar-ALS, and in patients with more advanced disease.

\section{Memantine}

Memantine is a low-affinity, noncompetitive antagonist of both open-channel N-methyl-D-aspartate (NMDA) and $\alpha$-calcium-permeable-amino-3-hydroxy-5-methyl4-isoxazole propionic acid (AMPA) glutamate receptors. ${ }^{13,14}$ It permits the blockade of excessive NMDA receptors activity, without disrupting normal synaptic transmission. ${ }^{13}$ Various in vitro and in vivo models of excitotoxicity showed that memantine has neuroprotective properties ${ }^{14}$ and the drug has been used clinically with excellent safety in various neurodegenerative disorders, including Alzheimer's disease. ${ }^{15}$ Two recent animal studies on SOD1 transgenic mice found that the drug is effective in slowing progression and increasing survival of transgenic mice. ${ }^{16,17}$ In one study, the administration of memantine had therapeutic effects, even when given at symptoms onset. ${ }^{17}$ Data on ALS patients are lacking, although one phase II clinical trial in US and combined phase II-III clinical trials are ongoing. ${ }^{18}$ 
Table I List of drugs tested in ALS, with hypothetical mechanisms of action and currently available results

\begin{tabular}{|c|c|c|}
\hline Compound & $\begin{array}{l}\text { Mechanism } \\
\text { of action }\end{array}$ & Principal results \\
\hline Riluzole & Antiglutamatergic & $\begin{array}{l}\text { Preclinical studies with positive results } \\
\text { In three clinical trials was associated with increase in survival of about two } \\
\text { months } \\
\text { Results from population-based studies indicated an increase in survival rates at } \\
12 \text { months by } 10 \% \text { and in median survival by } 4-6 \text { months } 10,11 \\
\text { A trend for stronger benefice amongst bulbar-onset ALS and patients } \\
\text { aged }>70 \text { years was also observed }{ }^{10,11} \\
\text { The favorable effect was transient, as it was lost in prolonged follow-up } \\
\text { (after } 18 \text { months) })^{10,11}\end{array}$ \\
\hline Memantine & Antiglutamatergic & $\begin{array}{l}\text { Neuroprotective in in vitro and in vivo studies }{ }^{14} \\
\text { Positive preclinical studies on SODI transgenic mice } \\
\text { No data on humans }\end{array}$ \\
\hline L-Arginine & Antiglutamatergic & $\begin{array}{l}\text { Positive preclinical studies on SODI transgenic mice }{ }^{19} \\
\text { Lower plasma L-arginine levels in ALS patients }{ }^{20} \\
\text { No clinical trials on ALS patients }\end{array}$ \\
\hline Ceftriaxone & Antiglutamatergic & $\begin{array}{l}\text { Positive preclinical studies on SODI transgenic mice }{ }^{21,22} \\
\text { Limited data on humans }\end{array}$ \\
\hline Cobalamin & Antiglutamatergic & $\begin{array}{l}\text { Two trials on SODI transgenic mice gave positive results }{ }^{26,27} \\
\text { A small double-blind trial found that short term (four weeks) high-dosage } \\
(0.5 \mathrm{mg} / \text { day) was effective in improving compound motor action potential, used } \\
\text { as indicator of lower motoneuron number }{ }^{28} \\
\text { Patients with a good response to treatment presented slower disease } \\
\text { progression (disease duration: } 23 . I \text { vs } 18.8 \text { months; } P=0.02)^{28} \\
\text { The clinical benefit was however transient, as it was followed by deterioration } \\
\text { after I-3 months }{ }^{28}\end{array}$ \\
\hline Talampanel & Antiglutamatergic & $\begin{array}{l}\text { Prolongs survival in SODI transgenic mice } \\
\text { In a phase II study on } 60 \text { patients with ALS showed safe and well tolerated } \\
\text { results } \\
\text { No data on efficacy }\end{array}$ \\
\hline $\begin{array}{l}\mathrm{N} \text {-acetylated alpha-linked } \\
\text { acidic dipeptidase }\end{array}$ & Antiglutamatergic & $\begin{array}{l}\text { Positive results from in vivo studies on motor neurons }{ }^{31} \text { and in vivo studies on } \\
\text { SODI transgenic mice } 30 \\
\text { No data on safety and efficacy in ALS patients }\end{array}$ \\
\hline Topiramate & Antiglutamatergic & $\begin{array}{l}\text { Preclinical studies with conflicting results: effective in vitro, but not in vivo }{ }^{32} \\
\text { A randomized clinical trial showed no benefits. Patients receiving the drug had } \\
\text { more pulmonary emboli, deep vein thrombosis, and renal calculi }{ }^{33}\end{array}$ \\
\hline Gabapentin & Antiglutamatergic & $\begin{array}{l}\text { Preclinical results with gabapentin suggested that this agent may prolong motor } \\
\text { neuron survival }{ }^{34} \\
\text { A phase II randomized trial found a slowing of the rate of strength decline }{ }^{35} \\
\text { A phase III clinical trial found no benefit on survival }\left.\right|^{36}\end{array}$ \\
\hline Lamotrigine & Antiglutamatergic & $\begin{array}{l}\text { Animal model with axotomy gave positive results }{ }^{38} \\
\text { Two small sample randomized clinical trials found no beneficial effects on } \\
\text { survival and markers of motor performances }{ }^{39,40}\end{array}$ \\
\hline r-IGF-I & Neuroprotective & $\begin{array}{l}\text { In vitro and in vivo studies gave positive results }{ }^{41} \\
\text { A first clinical trial found beneficial effect, }{ }^{42} \text { while two further clinical trials gave } \\
\text { negative results }{ }^{43,44}\end{array}$ \\
\hline Mechano-growth factor & Neuroprotective & $\begin{array}{l}\text { A variant of IGF-I was more effective on survival of SODI transgenic mice, } \\
\text { compared to IGF- }\left.\right|^{47} \\
\text { No data on humans }\end{array}$ \\
\hline Ciliary neurotrophic factor & Neuroprotective & $\begin{array}{l}\text { Preclinical study with positive results }{ }^{48} \\
\text { Two clinical trials revealed it was ineffective in ALS patients } s^{50,51} \\
\text { A trend for higher serious adverse events was noted }\end{array}$ \\
\hline EPO & $\begin{array}{l}\text { Neuroprotective } \\
\text { Anti-inflammatory } \\
\text { Antiapoptotic }\end{array}$ & $\begin{array}{l}\text { Neuroprotective effects in in vivo and in vitro studies } \\
\text { Safe and well tolerated in a phase II clinical trial } \\
\text { No data on efficacy in humans }\end{array}$ \\
\hline
\end{tabular}


Table I (Continued)

Principal results

\begin{tabular}{|c|c|}
\hline Compound & $\begin{array}{l}\text { Mechanism } \\
\text { of action }\end{array}$ \\
\hline VEGF & $\begin{array}{l}\text { Neuroprotective (against } \\
\text { excitotoxicity) }\end{array}$ \\
\hline rh-GSF & $\begin{array}{l}\text { Neuroprotective } \\
\text { Antiapoptotic }\end{array}$ \\
\hline rh-HGF & $\begin{array}{l}\text { Neuroprotective } \\
\text { Antiapoptotic } \\
\text { Antiglutamatergic }\end{array}$ \\
\hline BDNF & Neuroprotective \\
\hline GDNF & Neuroprotective \\
\hline Xaliproden & Neuroprotective \\
\hline Coenzyme Q & $\begin{array}{l}\text { Antioxidant } \\
\text { Mitochondrial cofactor }\end{array}$ \\
\hline Creatine & $\begin{array}{l}\text { Antioxidant } \\
\text { Mitochondrial cofactor }\end{array}$ \\
\hline
\end{tabular}

Neuroprotective (against excitotoxicity)

Mitochondrial cofactor

Vitamin E Antioxidant

\begin{tabular}{|c|c|}
\hline Edavarore & $\begin{array}{l}\text { Antioxidant } \\
\text { (Free-radicals scavenger) }\end{array}$ \\
\hline$R(+)$ Pramipexole & $\begin{array}{l}\text { Antioxidant } \\
\text { Antiapoptotic }\end{array}$ \\
\hline AEOL-10150 & Antioxidant \\
\hline $\begin{array}{l}\text { Ammonium } \\
\text { tetrathiomolybdate }\end{array}$ & $\begin{array}{l}\text { Antioxidant } \\
\text { (copper-chelating drug) }\end{array}$ \\
\hline $\mathrm{N}$-acetylcysteine & Antioxidant \\
\hline TROI9622 & Antioxidant \\
\hline Tamoxifen & Antioxidant \\
\hline
\end{tabular}

VEGF polymorphisms have been associated with an increased risk for $\mathrm{ALS}^{23}$

Preclinical studies found efficacy on SODI transgenic mice ${ }^{56,57}$

No data regarding safety, tolerability or efficacy in humans.

The compound requires intrathecal delivery ${ }^{23}$

A phase II clinical trial is underway ${ }^{24}$

Preclinical studies on ALS animal models gave positive results ${ }^{60}$

Safe and well tolerated in two small sample open-label pilot studies ${ }^{6,62}$

One study found a trend of slowing disease progression ${ }^{62}$

Prolonged survival in different studies on SODI animal models ${ }^{63-65}$

Safety or efficacy data in patients with ALS are lacking and the compound

requires intrathecal delivery

Positive results in preclinical studies on ALS animal models ${ }^{68,69}$

A trend for prolonged survival after the subcutaneous infusion of BDNF was found in a phase $\mathrm{I} / \mathrm{Il}$ study ${ }^{70}$

A large phase III placebo-controlled clinical trial found no beneficial effect from subcutaneous administration of BDNF ${ }^{71}$

Intrathecal infusion was safe and well tolerated in $25 \mathrm{ALS}$ patients ${ }^{66}$

Treatment with GDNF mediated by either

an adeno-associated virus vector ${ }^{72-74}$ or

by mesenchimal stem cells ${ }^{75,76}$ was effective in preclinical in vitro and in vivo studies No data on ALS patients

Modest effects on vital capacity but not on survival in phase II and III clinical trials ${ }^{79,80}$

Prolongs survival in SODI transgenic mice ${ }^{81}$

Safe and well tolerated in a recent phase II clinical trial ${ }^{82}$

Not effective in a phase II futility trial ${ }^{83}$

Preclinical studies with positive results ${ }^{23,84}$

Several phase II clinical trials on ALS patients using doses up to $10 \mathrm{~g} /$ day gave negative results ${ }^{85-87}$

Treatment with $20 \mathrm{~g} /$ day increases maximal isometric power in ALS patients ${ }^{88}$

Clinical trials using high dosage or a combination with celecoxib are ongoing ${ }^{24}$

Effective in ALS animal models?

High intake of vitamin E was associated with a $50 \%-60 \%$ decreased risk of developing ALS, in a recent retrospective case-control study ${ }^{93}$

Safe, well tolerated, but not effective in two double blind, placebo-controlled, clinical trials as add-on to riluzole ${ }^{91,92}$

Preclinical studies with positive results ${ }^{94}$

Was safe and well tolerated and there was a suggestion of slowed disease progression in an open-label phase II study ${ }^{95}$

Prolonged survival in an animal study on SODI transgenic mice ${ }^{96}$

A nonsignificant reduction in disease progression was observed in a recent phase II clinical study ${ }^{97}$

Effective in prolonging survival in animal study on SODI transgenic mice ${ }^{99-101}$ In a recent open-label study on patients with ALS was safe and well tolerate ${ }^{102}$

Positive preclinical studies on SODI transgenic mice ${ }^{104}$

No data on humans

Prolonged survival and delayed onset of motor impairment in ALS animal study 105

Not effective in a double-blind placebo-controlled clinical trial ${ }^{106}$

Positive results from in vitro and in vivo studies ${ }^{107}$

No data on ALS patients

A phase II clinical trial indicated a trend for survival benefit with administration of tamoxifen at the dose of $\geq 20 \mathrm{mg} /$ day ${ }^{108}$ 
Table I (Continued)

\begin{tabular}{|c|c|c|}
\hline Compound & $\begin{array}{l}\text { Mechanism } \\
\text { of action }\end{array}$ & Principal results \\
\hline Minocycline & $\begin{array}{l}\text { Antiapoptotic } \\
\text { Anti-inflammatory }\end{array}$ & $\begin{array}{l}\text { Extends survival in mouse models of some neurological conditions }{ }^{109-111} \\
\text { Safe and well tolerated in phase-II clinical trials }{ }^{112} \\
\text { A recent multicenter, randomized placebo-controlled phase III trial found that } \\
\text { minocycline in escalating doses of up to } 400 \mathrm{mg} / \text { day for nine months has a harmful } \\
\text { effect on patients with ALS } 113\end{array}$ \\
\hline $\mathrm{TCH}-346$ & Antiapoptotic & $\begin{array}{l}\text { A small sample double-blind placebo controlled clinical trial conducted find no } \\
\text { beneficial effects } 114\end{array}$ \\
\hline zVAD-fmk & Antiapoptotic & $\begin{array}{l}\text { Significantly delayed disease onset and prolonged survival in SOD I transgenic } \\
\text { mice }{ }^{116} \\
\text { Data on ALS patients are still not available }\end{array}$ \\
\hline Pentoxifylline & Antiapoptotic & $\begin{array}{l}\text { A large phase II randomized clinical trial found that the drug is not effective in } \\
\text { ALS and should be avoided in patients treated with riluzole }{ }^{117}\end{array}$ \\
\hline Celecoxib & $\begin{array}{l}\text { Anti-inflammatory (cyclo- } \\
\text { oxygenase-2 inhibitor) }\end{array}$ & $\begin{array}{l}\text { Positive preclinical studies on SODI transgenic mice } 19,120 \\
\text { A double-blind, placebo-controlled, clinical trial demonstrated that celecoxib } \\
\text { ( } 800 \mathrm{mg} / \text { day) was safe but did not have a beneficial effect on patients with } \text { ALS }^{121} \\
\text { A clinical trial evaluating the association with creatine at high dose is underway }{ }^{24}\end{array}$ \\
\hline Glatiramer acetate & $\begin{array}{l}\text { Anti-inflammatory } \\
\text { Antiglutamatergic growth } \\
\text { factor-stimulating effects }\end{array}$ & $\begin{array}{l}\text { Conflicting results from preclinical studies: some studies found that it prolonged } \\
\text { survival in SODI mutant mice, }{ }^{124} \text { while others did not }{ }^{125} \\
\text { Was safe and well tolerated in a phase II trial }{ }^{126} \\
\text { A double-blind, randomized, placebo-controlled, multicenter trial confirmed } \\
\text { safety and tolerability but did not show any beneficial effect }{ }^{127}\end{array}$ \\
\hline AM-I24I & $\begin{array}{l}\text { Anti-inflammatory (via } \\
\text { cannabinoid receptors) }\end{array}$ & $\begin{array}{l}\text { Delayed the disease progression in animal studies }{ }^{128,129} \\
\text { No data on humans are available }\end{array}$ \\
\hline Celastrol & $\begin{array}{l}\text { Anti-inflammatory } \\
\text { Antioxidant } \\
\text { Interfere with protein } \\
\text { aggregation (by heat-shock } \\
\text { protein induction) }\end{array}$ & $\begin{array}{l}\text { Significantly improved weight loss, motor performance and } \\
\text { delayed the onset of ALS in SODI transgenic mice }{ }^{130} \\
\text { No data on humans are available }\end{array}$ \\
\hline Thalidomide & Anti-inflammatory & $\begin{array}{l}\text { Enhanced motor performance, decreased motor neuron cell death, and } \\
\text { significantly increased the life span in animal studies }{ }^{131} \\
\text { A small open-label study find no improvement in progression of the disease and } \\
\text { a high risk for side effects }{ }^{132}\end{array}$ \\
\hline Nordihydroguaiaretic acid & $\begin{array}{l}\text { Anti-inflammatory } \\
\text { Antiglutamatergic }\end{array}$ & $\begin{array}{l}\text { Extends survival and slows disease progression in animal studies }{ }^{135} \\
\text { No data are available on humans }\end{array}$ \\
\hline Pioglitazone & Anti-inflammatory & $\begin{array}{l}\text { Significantly improved muscle strength and body weight, delayed disease onset, } \\
\text { and prolonged survival in SODI transgenic mice }{ }^{136-138} \\
\text { No data are available on humans }\end{array}$ \\
\hline RO-28-2653 & $\begin{array}{l}\text { Anti-inflammatory (inhibits } \\
\text { matrix metalloproteases) }\end{array}$ & $\begin{array}{l}\text { Prolongs survival in ALS SODI transgenic mice }{ }^{139} \\
\text { No data on humans are available }\end{array}$ \\
\hline ONO-2506 & $\begin{array}{l}\text { Anti-inflammatory } \\
\text { Restores astrocytes } \\
\text { Antiglutammatergic }\end{array}$ & $\begin{array}{l}\text { Limited data on preclinical studies and on humans }{ }^{140} \\
\text { Trials have been however recently completed }\end{array}$ \\
\hline Lithium & $\begin{array}{l}\text { Inductor of autophagy } \\
\text { Antioxidant }\end{array}$ & $\begin{array}{l}\text { Effective in preclinical studies on SODI transgenic mice }{ }^{141} \\
\text { In a small sample open label study delayed disease progression in } 44 \text { patients } \\
\text { affected by ALS'141 } \\
\text { Two large clinical trials are ongoing }{ }^{24}\end{array}$ \\
\hline Sodium phenylbutyrate & $\begin{array}{l}\text { Inhibit protein aggregation } \\
\text { (histone deacetylase } \\
\text { inhibitor) }\end{array}$ & $\begin{array}{l}\text { Promotes cell survival, alone or in combination with riluzole in animal } \\
\text { studies }{ }^{144,145} \\
\text { Safe and well tolerated in a recent open-label study }{ }^{146}\end{array}$ \\
\hline Valproate & $\begin{array}{l}\text { Inhibit protein aggregation } \\
\text { (histone deacetylase } \\
\text { inhibitor) }\end{array}$ & $\begin{array}{l}\text { Preclinical studies on SODI mutant mice gave discordant results; }{ }^{149-152} \text { some } \\
\text { studies found that it prolongs survival, }{ }^{149,150} \text { while others did not }{ }^{151,152} \\
\text { Safe but not effective in a recent sequential clinical trial }{ }^{153}\end{array}$ \\
\hline
\end{tabular}

(Continued) 
Table I (Continued)

\begin{tabular}{lll}
\hline Compound & $\begin{array}{l}\text { Mechanism } \\
\text { of action }\end{array}$ & Principal results \\
\hline Scriptaid & $\begin{array}{l}\text { Inhibit protein aggregation } \\
\text { (histone deacetylase }\end{array}$ & $\begin{array}{l}\text { Preliminary positive results in cultural cells transfected with SODI } \\
\text { No data on animal models and humans are available }\end{array}$ \\
& $\begin{array}{l}\text { inhibitor) } \\
\text { Ariclomol } \\
\text { (by heat-shock protein } \\
\text { induction) }\end{array}$ & $\begin{array}{l}\text { Effective in preclinical studies } \\
\text { S55,156 }\end{array}$ \\
& Safe and well tolerated in a phase II clinical trial ${ }^{157}$ \\
\end{tabular}

Abbreviations: ALS, amyotrophic lateral sclerosis; r-IGF-I, recombinant insulin-like growth factor; EPO, recombinant human erythropoietin; VEGF, vascular endothelial growth factor; rh-GSF, recombinant human granulocyte-macrophage colony-stimulating factor; rh-HGF, recombinant human hepatocyte growth factor; BDNF, brain-derived neurotropic factor; GDNF, glial cell-derived neurotropic factor; SODI, superoxide dismutase-I.

\section{L-Arginine}

L-Arginine is a semiessential amino acid that serves as sole substrate for enzymes involved in diverse cell processes. Preclinical studies have found that L-arginine protects cultured motor neurons from glutamate excitotoxic injury. ${ }^{19}$ The mechanism underlying these favorable effects is still not known but may be related to the synthesis of neuroprotective polyamines, essential for neuronal survival and regeneration. ${ }^{19}$ L-Arginine supplementation in SOD1 transgenic ALS mice, administrated both prior to and after the onset of motor neuron degeneration, significantly slowed the progression of neuropathology in lumbar spinal cord, delayed onset of motor dysfunction, and prolonged life span. ${ }^{19}$ Moreover, lower plasma L-arginine concentrations have been reported in ALS patients, probably due to malnutrition associated with advanced ALS. ${ }^{20}$ Although L-arginine has potent in vitro and in vivo neuroprotective properties and may be a candidate for therapeutic trials in ALS, data on humans are lacking. ${ }^{8,18}$

\section{Ceftriaxone}

Ceftriaxone, a beta-lactam antibiotic, modulates the expression of glutamate transporter GLT1 via gene activation and may also act as metal chelator. ${ }^{21}$ Preclinical studies demonstrated that it prolongs survival in different animal models of ALS..$^{21,22}$ This compound has been used extensively in humans and is safe. ${ }^{23}$ However, intravenous administration is required and there is limited safety experience in ALS patients. ${ }^{23} \mathrm{~A}$ combined longterm clinical trial of intravenous treatment with ceftriaxone has been started. The study consists of three stages. The first two stages will evaluated brain penetration, safety and side effects. The third stage will determine whether the study drug prolongs survival and slows decline in function due to ALS. ${ }^{18,24}$

\section{Cobalamin}

Vitamin B12 (cobalamin) has multiple protective effects that can be potentially relevant in ALS. Accumulating evidence indicates that B-vitamin inhibits the cytotoxicity induced by NMDA and protects cultured neurons against glutamate excitotoxicity. ${ }^{25}$ Cobalamin also has antioxidant and antiapoptotic properties. ${ }^{26}$ In two controlled trials on G93A SOD1 transgenic mice, multivitamin therapy with cobalamin, folic acid and pyridoxine significantly prolonged average lifespan improved motor performance and delayed disease onset of treated mice, compared to controls. ${ }^{26,27}$ Furthermore, cobalamin administrated presymptomatically significantly delayed the onset of motor neuron disease in one of the studies. ${ }^{26}$ In a small sample double blind clinical trial conducted on 24 Japanese ALS

Table 2 List of compounds undergoing clinical trials for ALS ${ }^{163}$

\begin{tabular}{lll}
\hline Compound & Phase & Mechanism of action \\
\hline Ariclomol & II/III & Heat-shock protein induction \\
Ceftriaxone & II/III & Antiglutamatergic \\
Cobalamin & II/III & Antiglutamatergic \\
Creatine & II/III & Antioxidant \\
Celecoxib & & Anti-inflammatory \\
Edavarore & II/III & Free-radicals scavenger \\
& & Reduces mutant SODI deposition \\
Lithium & a) II/III & Inductor of autophagy \\
Memantine & b) II/III & \\
Pioglitazone & II/III & Antiglutamatergic \\
R(+) pramipexole & II & Anti-inflammatory \\
& & Antioxidant \\
Talampanel & II & Antiapoptotic \\
Thalidomide & a) I & Antiglutamatergic \\
& b) II & \\
Valproate & II/III & Inhibits protein aggregation by acting as \\
VEGF & & a histone deacetylase inhibitor \\
& II & Protects motor neurons against \\
excitotoxicity
\end{tabular}

Abbreviations: ALS, amyotrophic lateral sclerosis; SOD I, superoxide dismutase- I; VEGF, vascular endothelial growth factor. 
patients short term (four weeks) high-dosage $(0.5 \mathrm{mg} /$ day $)$ administration of methyl-cobalamin was effective in improving compound motor action potential, used as indicator of lower motoneuron number. ${ }^{28}$ Patients with a good response to treatment presented slower disease progression (disease duration: 23.1 vs 18.8 months; $P=0.02$ ) and predominant lower motor neuron involvement, compared to nonresponders. ${ }^{28}$ The clinical benefit however was transient, as it was followed by deterioration after 1-3 months. ${ }^{28}$ A large-scale long-term clinical trial is ongoing in Japan to evaluate the long-term efficacy and the safety of ultrahigh-dose methylcobalamin for ALS. ${ }^{29}$

\section{Talampanel}

Talampanel is a noncompetitive modulator of glutamate AMPA glutamate receptors primarily developed as an antiepileptic agent. Talampanel significantly prolonged survival in SOD1 ALS transgenic mice. ${ }^{8}$ In a phase II study on 60 patients with ALS, talampanel was safe and well tolerated. ${ }^{8,23}$ A trend for slower decline in ALS Functional Rating Scale (ALS-FRS) score was also observed in the treated subgroup, although the study was not powered to detect efficacy. ${ }^{8,23}$ Therefore, there are still no data on its efficacy on patients with ALS.

\section{$\mathrm{N}$-acetylated alpha-linked acidic dipeptidase (NAALADase)}

$\mathrm{N}$-acetylated alpha-linked acidic dipeptidase (NAALADase) is an inhibitor of glutamate carboxypeptidase II, which converts the neuropeptide $\mathrm{N}$-acetylaspartylglutamate to glutamate. ${ }^{30}$ Glutamate carboxypeptidase II inhibitors may provide neuroprotection by simultaneously decreasing glutamate production and inhibiting glutamate release. ${ }^{30}$ Preclinical in vitro studies in SOD1 transgenic mice found that treatment with selective inhibitors of glutamate carboxypeptidase II significantly delays the onset of clinical symptoms and prolongs life. ${ }^{30}$ Glutamate carboxypeptidase II inhibitors were protective against histological abnormalities induced by mutant SOD1 in in vitro studies on motor neurons cultures. ${ }^{31}$ In phase I single dose and repeat dose trials treatment with NAALADase was safe and well tolerated by both healthy volunteers and diabetic patients..$^{30}$ There are however still no data on safety and efficacy in ALS patients.

\section{Topiramate}

Topiramate is an anticonvulsant with antiglutamatergic properties. It reduces glutamate release from neurons and blocks AMPA receptors. In vitro studies found that topiramate protects motor neurons in an organotypic spinal cord culture system in which glutamate transport is inhibited by pharmacological blockade. ${ }^{32}$ Conversely, the drug did not increase survival in G93A SOD1 transgenic mice. ${ }^{32}$

A randomized placebo controlled clinical trial has been recently conducted in 296 ALS patients from the US. Patients were randomized (2:1) to receive topiramate (maximum tolerated dose up to $800 \mathrm{mg} /$ day) or placebo for 12 months. ${ }^{33}$ At the dosages studied, topiramate did not have a beneficial effect for patients with ALS. Moreover, high-dose topiramate treatment was associated with a faster rate of decline in muscle strength and with an increased risk for several adverse events, such as pulmonary emboli, deep vein thrombosis, and renal calculi. ${ }^{33}$

\section{Gabapentin}

Gabapentin is another antiepileptic drug with antiglutamatergic properties. Gabapentin may reduce the pool of releasable glutamate and thus decrease glutamate excitotoxicity. ${ }^{34}$ Preclinical studies with gabapentin suggested that this agent may prolong motor neuron survival. ${ }^{35} \mathrm{~A}$ six-month phase II randomized trial in 150 patients with ALS found a nonstatistically significant trend towards slowing of the rate of strength decline in patients taking gabapentin (up to 2,400 mg day), compared with those taking placebo (mean difference $24 \%$, median $37 \%$; $P=0.057) .{ }^{35}$ In a phase III randomized placebo controlled clinical trial 204 ALS patients received oral gabapentin 3,600 mg or placebo daily for nine months. The mean rate of decline of the arm muscle strength was not significantly different between the groups. ${ }^{36}$ Moreover, there was no beneficial effect on the rate of decline of other secondary measures, as vital capacity, survival and ALS-FRS score. ${ }^{36}$ Confirming these findings, a recent small proton magnetic resonance spectroscopy study on 18 ALS patients showed that treatment with gabapentin was not associated with improvement in spectroscopic markers of neuronal integrity in motor and nonmotor cerebral regions. ${ }^{37}$

\section{Lamotrigine}

Lamotrigine is an antiepileptic drug that inhibits glutamate release. ${ }^{38}$ Treatment with lamotrigine was associated with a reduction in motor neuron loss in an animal model using axotomy ${ }^{38}$ Two small sample, randomized phase I clinical trials found no beneficial effects on survival and markers of motor performances on total 97 ALS patients. ${ }^{39,40}$

\section{Neurotrophic factor}

\section{Recombinant insulin-like growth factor (rIGF-I)}

Recombinant insulin-like growth factor (r-IGF-1) is a potent neurotrophic factor that has neuroprotective properties in the central and peripheral nervous systems. ${ }^{41}$ Due to the efficacy 
of IGF-I in the treatment of other diseases and its ability to promote neuronal survival in both in vitro and in vivo studies, IGF-I has been extensively studied in ALS. ${ }^{23,41}$

The efficacy and safety of r-IGF-1in ALS has been tested in three clinical trials. ${ }^{42-44}$ With the exception of an increased risk of injection site reactions with r-IGF-I, the drug showed otherwise safe and well tolerated results. However, the benefit on survival was inconsistent across the studies. One study showed a slowing in functional decline, ${ }^{42}$ whilst no benefit was observed in the second. ${ }^{43}$ The combined analysis from both trials performed by the Cochrane Group showed a trend towards for beneficial effect favoring the treated group. ${ }^{45}$ A third placebo-controlled trial has been recently completed. ${ }^{44}$ There was no difference between treatment groups in the primary and secondary outcome measures after a two-year follow-up period. ${ }^{44}$ In conclusion, r-IGF-I is well tolerated but, although so far is the only agent other than riluzole to show on any ALS markers of disease progression, can not be considered beneficial for patients with ALS. Recently, an adenoassociated virus has been engineered to contain the gene for IGF-1 (IGF-1/AAV). ${ }^{23}$ Theoretically, after the intramuscular injection, this vector could allow to deliver IGF-1 to motor neurons. ${ }^{23}$ Preclinical studies revealed that IGF-1/AAV can prolong survival in SOD1 ALS transgenic mice. ${ }^{46}$ However, there are no data on safety, tolerability or pharmacokinetics of IGF-1/AAV in humans with ALS.

\section{Mechano-growth factor (MGF)}

The mechano-growth factor (MGF), an IGF-I splice variant, has been shown to have greater neuroprotective effects than IGF-I in a number of models of neurodegeneration. ${ }^{23}$ In an animal study on SOD1 transgenic mice the intramuscular administration of a mammalian expression plasmid containing MGF or, for comparison, the IGF-I DNA sequence resulted in a significant improvement in hind-limb muscle strength, and an increase in motor unit and motor neuron survival. ${ }^{47}$ Significantly more motor neurons survived in MGF treated mice. ${ }^{47}$ There are still no data on safety and efficacy in humans.

\section{Ciliary neurotrophic factor (CNTF)}

Ciliary neurotrophic factor (CNTF) is a neuroactive cytokine found in Schwann cells, which seems to be released in response to nerve injury. ${ }^{23} \mathrm{CNTF}$ maintains survival of adult motor neurons and mice lacking the CNTF gene develop mild, progressive motor neuron loss. ${ }^{48}$ In a recent study, serum level of CNTF was significantly higher in ALS patients than in controls. ${ }^{49}$ There was no difference between familial and sporadic ALS, and a trend for higher levels was observed in patients with spinal-onset ALS, compared to patients with a bulbar onset of the disease. ${ }^{49}$ ALS patients in two trials $(n=1,300)$ were treated with subcutaneous CNTF. ${ }^{50,51}$ No significant difference in either primary or secondary outcomes was observed between CNTF and placebo groups. ${ }^{50-52}$ However, a significant increase of the incidence of several adverse events was noted in groups treated with higher doses of CNTF. ${ }^{52}$ Therefore CNTF can not be considered beneficial for patients with ALS.

\section{Recombinant human erythropoietin (EPO)}

Recombinant human erythropoietin (EPO) is used to stimulate red blood cell production in patients with anemia. Preclinical studies in different models of peripheral and central nervous system diseases revealed that EPO has also anti-inflammatory and antiapoptotic properties. ${ }^{53,54} \mathrm{~A}$ recent phase II double-blind, randomized, placebo-controlled study on 23 patients showed that treatment with subcutaneous EPO was safe and well tolerated. ${ }^{55}$ However, larger studies are warranted to confirm safety and to investigate different dose schedule and efficacy.

\section{Vascular endothelial growth factor (VEGF)}

VEGF polymorphisms have been associated with an increased risk for ALS in some, but not all populations. ${ }^{23}$ Therefore VEGF deficiency may play a role in the pathogenesis of ALS. The most important limitation as for other growth factors, is that requires invasive administration (intraventricular or via viral vectors). ${ }^{23}$ Preclinical studies on different ALS animal models found that intracerebral or intraspinal treatment with VEGF prolongs survival and reduces disease progression, particularly when given before the onset of symptoms. ${ }^{56,57}$ In vitro studies showed that VEGF protects motor neurons against excitotoxicity. ${ }^{58}$ Finally, intratechal transplantation of neural stem cells overexpressing VEGF was effective in several animal studies. ${ }^{59}$ There are, however, no data regarding safety, tolerability or efficacy in humans, although a phase II clinical trial is ongoing. ${ }^{24}$

\section{Recombinant human granulocyte-stimulating factor (rh-GSF)}

Recombinant human granulocyte-stimulating factor (rh-GSF), used to stimulate white blood cell production in patients with leucopenia, has been proposed for ALS because the GSF receptor is expressed by motor neurons, has neurotropic effects, and protects cultured motor neuronal cells from apoptosis. ${ }^{60}$ In a recent animal study, continuous subcutaneous delivery of GSF, given at the stage of the disease where muscle denervation is already evident, significantly improved motor performance, delayed the onset of severe motor impairment and prolonged overall survival 
of SOD1 transgenic mice model. ${ }^{60}$ In two small sample open-label pilot studies on 39 ALS patients overall, rh-GSF was safe and well tolerated. ${ }^{61,62}$ One study found a trend of slowing disease progression following rh-GSF treatment, as shown by lower decline of quality of life and ALS-FRS score. ${ }^{62}$ Larger studies are needed.

\section{Recombinant human hepatocyte growth factor (rh-HGF)}

Recombinant human hepatocyte growth factor (rh-HGF) has, in addition to its neurotropic effects, antiapoptotic and antiglutammatergic properties. ${ }^{63,64}$ Intrathecal aministration and gene therapy significantly prolonged survival in different studies on SOD1 animal models, even if delivered at symptom onset. ${ }^{63-65}$ A recent immunohistochemical study on both familial (SOD1) and sporadic ALS found that HGF is expressed on the anterior horn cells of the spinal cord, supporting the hypothesis that disruption of HGF system thereby contributes to the acceleration of neuronal degeneration in FALS patients. ${ }^{66}$

However, safety or efficacy data in patients with ALS are lacking and the compound requires intrathecal administration.

\section{Brain-derived neurotrophic factor (BDNF)}

Brain-derived neurotrophic factor (BDNF) is a neurotrophin that supports the survival and growth of developing motor neurons. ${ }^{67}$ Preclinical studies in several animal models found that BDNF treatment significantly prolongs survival and slows the loss of motor neurons. ${ }^{8,68,69}$ In phase I/II study, the subcutaneous infusion of BDNF increased survival and retard loss of pulmonary function in ALS patients, ${ }^{70}$ but a large phase III placebo-controlled clinical trial of subcutaneous administration of 25 or $100 \mu \mathrm{g} / \mathrm{kg} \mathrm{n} 1.135 \mathrm{ALS}$ patients failed to demonstrate a statistically significant effect of BDNF on survival. ${ }^{71}$ Post hoc analyses revealed a statistically significant benefit in ALS patients with an early respiratory impairment. Higher subcutaneous dosage or an intrathecal delivery have been proposed to emphasize the possible beneficial effects of the drug. Recently, in a phase I/II trial intrathecal infusion of recombinant methionyl human BDNF in doses of up to $150 \mu \mathrm{g} /$ day showed safe and well tolerated results in $25 \mathrm{ALS}$ patients, although reversible mild sensory symptoms were reported in the higher-dosage subgroup. ${ }^{67}$ Studies on the efficacy of intrathecal BDNF are therefore required.

\section{Glial cell-derived neurotrophic factor (GDNF)}

Glial cell-derived neurotrophic factor (GDNF) has a potent trophic effect on motor neurons. ${ }^{71}$ Several preclinical in vitro and in vivo studies found that treatment with GDNF mediated by either an adeno-associated virus vector ${ }^{72-74}$ or by mesenchimal stem cells ${ }^{75,76}$ is effective in prolonging motor neurons survival. Conversely, studies from patients with sporadic ALS gave conflicting results. ${ }^{77,78}$ Increased cerebrospinal fluid levels of GDNF in patients with ALS compared to controls ${ }^{77}$ and upregulation of GDNF gene in both spinal cord and muscle of sporadic ALS have been indeed observed. ${ }^{77,78}$ These findings indicate that the capacity to synthesize GDNF is enhanced in ALS. Clinical trials of GDNF in ALS patients are however lacking.

\section{Xaliproden}

Xaliproden is a nonpeptidic compound with growth factor activities. ${ }^{8}$ A double-blind, placebo-controlled phase II study conducted in 54 ALS patients treated for up to 32 weeks showed a significantly slower rate of deterioration in vital capacity (VC) $(43 \% ; P=0.046)$ in xaliproden-treated patients. ${ }^{79}$ Two randomized phase III clinical trials have been conducted: one with xaliproden and riluzole and the other with xaliproden alone. Two primary endpoints were defined: time to death, tracheostomy, or permanent assisted ventilation and time to VC of less than $50 \%{ }^{80}$ The drug demonstrated in both studies modest benefits for VC but not for the other endpoints. ${ }^{80}$ Therefore the drug is not significantly effective in ALS.

\section{Antioxidant Coenzyme Q 10}

Coenzyme Q 10 has multiple potential mechanisms that can be relevant in ALS. It acts as an antioxidant and an essential mitochondrial cofactor that facilitates electron transfer in the respiratory chain. ${ }^{23}$ Animal studies revealed that coenzyme Q 10 can prolong survival in SOD1 transgenic mice. ${ }^{81}$ In an open-label, dose-escalation study, doses up to 3,000 $\mathrm{mg}$ per day administered orally over eight months was safe and well tolerated in 31 patients with ALS. ${ }^{82}$ Conversely, results of a phase II futility trial on 185 patients showed no benefit on survival of $2,700 \mathrm{mg}$ daily oral treatment with coenzyme Q $10{ }^{83}$ Long term safety and efficacy in humans are limited, but several randomized studies in patients with ALS recently terminated recruitment. ${ }^{24}$

\section{Creatine}

Creatine has multiple potential effects that might be relevant in ALS, including its antioxidant properties, stabilization of the mitochondrial transition pore and facilitation of mitochondrial ATP synthesis. Important advantages of creatine are also its oral administration, elevate brain penetration and the excellent 
safety profile. ${ }^{8,23}$ Preclinical studies on SOD1 transgenic mice revealed that creatine significantly increases survival, when given before the onset of the disease..$^{23,84}$ Three double blind, placebo-controlled clinical trials on creatine monohydrate use have been recently conducted. ${ }^{85-87}$ In one clinical trial creatine was administrated at doses of $10 \mathrm{mg} /$ day over a 16 -month follow-up period, ${ }^{85}$ while the other two studies used a dosage of $5 \mathrm{mg}$ /day over a six- and nine-month period of observation. ${ }^{86,87}$ All these studies gave negative results as creatine failed to show a benefit on survival or multiple markers of disease progression. A possible explanation of these negative results may be that these trials did not use doses that optimize brain phosphocreatine levels, as preliminary results demonstrated that treatment with $20 \mathrm{~g}$ /day increases maximal isometric power in ALS patients. ${ }^{88}$ Alternatively, the combination of higher doses of creatine with other drugs may be used to maximize its benefit, as indicated by results from recent animal studies. ${ }^{89}$ Confirming these observations, an innovative phase II "selection" trial, in which creatine at $20 \mathrm{~g} /$ day was used in combination with either minocycline or celecoxib, found that the mean decline in ALS Functional Rating Scale (ALS-FRS) score was lower in the celecoxib-creatine group compared to the minocycline-creatine group and an historical cohort. ${ }^{90}$ The celecoxib-creatine may be therefore a preferable combination for further evaluation. Two clinical trials with high dose creatine and with celecoxib-creatine association are underway. ${ }^{24}$

\section{Vitamin $\mathrm{E}$}

Vitamin E (alpha-tocopherol) is the most important lipidsoluble antioxidant and protects cell membranes from oxidation by reacting with lipid radicals. ${ }^{23}$ Preclinical studies showed that treatment with vitamin E slows down the onset and progression of the paralysis in SOD 1 transgenic mice. ${ }^{9}$ Two double blind, placebo-controlled, clinical trials on ALS patients from Germany and France evaluated the safety and efficacy of high-dose vitamin E (5000 mg per day) when given added to riluzole, over a follow up period of 18 and 12 months, respectively. ${ }^{91,92}$ No significant difference between placebo and treatment group could be detected either in the primary or the secondary outcome measures, although the French trial observed that patients receiving alpha-tocopherol were less likely to progress from the milder state to the more severe state, according to the ALS Health State scale. ${ }^{91}$ In a recent retrospective case-control study, a high intake of vitamin $\mathrm{E}$ was associated with a 50\%-60\% decreased risk of developing ALS. ${ }^{93}$ Further clinical trials with longer follow-up or larger sample sizes are needed.

\section{Edavarone}

Edaravone (MCI-186) is an agent widely used for cerebral ischemia in Japan that acts as a free-radical scavenger. ${ }^{94}$ In a randomized blind trial, intraperitoneally administration of multiple doses of edaravone in an ALS mice model significantly slowed the motor decline and motor neuron degeneration of the transgenic mice, even when administered after the onset of the disease. ${ }^{94}$ Furthermore, high-dose edavarone treatment was associated with a significant decrease in the area of mutant SOD1 deposition in the spinal cord. ${ }^{94}$ The favorable effects of the drug might be attributable to its primary antioxidant properties or alternatively to the reduction of mutant SOD1 accumulation. ${ }^{94}$

In an open-label phase II study of 20 patients with ALS, the intravenous administration of edavarone was safe and well tolerated and there was a suggestion of slowed disease progression, measured by the ALS-FRS scale during the six-month treatment period, compared with the six months before the administration of edavarone. ${ }^{95}$ Treatment with edavarone also resulted in a marked reduction of 3-nitrotyrosine, a marker of oxidative stress. ${ }^{95}$ A phase III clinical trial is undergoing in Japan. ${ }^{24}$

\section{$\mathrm{R}(+)$ pramipexole}

$\mathrm{R}(+)$ pramipexole is the enantiomeric homolog of the dopamine agonist used in Parkinson's disease and can reduce oxidative stress in patients with ALS. ${ }^{96}$ In vitro and in vivo studies revealed that it is concentrated into the brain and mitochondria and efficiently scavenges reactive oxygen and nitrogen species, ${ }^{96,97}$ and blocks caspase activation. ${ }^{98}$ As it has less affinity for dopamine receptors than pramipexole, it should have fewer side effects. ${ }^{96}$ In SOD1 ALS transgenic mice, treatment with $\mathrm{R}(+)$ pramipexole prolongs survival. ${ }^{98}$ A small open-label dose-escalation study on 30 ALS patients revealed a nonsignificant $17 \%$ reduction in the rate of decline of ALS-FRS in the group of patients receiving the highest dosage $(60 \mathrm{mg} /$ day $) .{ }^{8,97}$ A study on safety and tolerability has just terminated the recruitment. ${ }^{23}$ Further studies are however warranted.

\section{AEOL- 10150}

The manganese porphyrin AEOL-10150, is a small-molecule antioxidant analogous to the catalytic site of superoxide dismutase, that scavenges peroxynitrite and other deleterious oxidants. ${ }^{8,23}$ It has been indicated as a potential subcutaneous treatment for ALS. ${ }^{98}$ The administration of AEOL-10150 at symptom onset markedly prolonged survival in SOD1 transgenic mice. ${ }^{99-101}$ Recently, the single dose subcutaneous 
treatment with AEOL-10150 was safe and well tolerated in 25 patients with ALS. ${ }^{102}$ A multiple dose phase II safety study is underway. ${ }^{24,102}$ Although there are limited data in humans with ALS, a recent meta-analysis of preclinical trials conducted on SOD1 transgenic mice found that AEOL-10150 can be considered the most promising compound for evaluation in a treatment trial. ${ }^{103}$

\section{Ammonium tetrathiomolybdate (TTM)}

Ammonium tetrathiomolybdate (TTM) is a copper-chelating drug that is capable of removing a copper ion from copperthiolate clusters, such as SOD1. ${ }^{104}$ A recent preclinical study on SOD1 transgenic mice found that treatment with TTM significantly delayed disease onset, slowed disease progression, and prolonged survival by approximately $20 \%, 42 \%$, and $25 \%$, respectively. ${ }^{104}$ TTM was also effective in depressing the spinal copper ion level and inhibiting the lipid peroxidation, with a significant suppression of SOD1 enzymatic activity in SOD1. ${ }^{104}$ There are still no data on humans.

\section{$\mathrm{N}$-acetylcysteine}

$\mathrm{N}$-acetyl-L-cysteine is an antioxidant agent that reduces free radical damage. ${ }^{8}$ Preclinical studies in transgenic mice with SOD1 mutation showed that N-acetyl-L-cysteine significantly extends survival and delayed onset of motor impairment. ${ }^{105}$ However, in a double-blind placebo-controlled clinical trial on 110 ALS patients, acetylcysteine $50 \mathrm{mg} / \mathrm{kg}$ daily subcutaneous infusion did not result in a major increase in 12-month survival or a reduction in disease progression. ${ }^{106}$ Therefore, the beneficial effects of cysteine in ALS seem questionable.

\section{TROI9622}

TRO19622 is a cholesr-4-en-3-one steroidal oxime identified via through-put screening. ${ }^{107}$ TRO19622 may increase mitochondrial stability by directly bounding to two components of the mitochondrial permeability transition pore: the voltagedependent anion channel and the translocator protein. ${ }^{107}$ In vitro studies found that TRO19622 promotes motor neuron survival in a dose-dependent manner. ${ }^{107}$ In vivo, TRO19622 rescued motor neurons from axotomy-induced cell death promoted nerve regeneration. ${ }^{107}$ Finally, treatment with TRO19622 significantly improved motor performances, delayed the onset of the disease and extended survival in SOD1transgenic mice. ${ }^{107}$ There are still no data on safety and efficacy on humans.

\section{Tamoxifen}

Tamoxifen is a selective estrogen receptor modulator that belongs, as TRO19622, to the family of steroidal eoximes. ${ }^{8}$
Along with the well known antineoplastic activity, tamoxifen may inhibit the action of protein kinase $\mathrm{C}$ and may bind the mitochondrial permeability transition pore. ${ }^{8}$ Preliminary results of a 24-month phase II clinical trial indicated a trend for survival benefit with administration of tamoxifen at the dose of $\geq 20 \mathrm{mg} /$ day. ${ }^{108}$

\section{Antiapoptotic Minocycline}

Minocycline is a tetracycline antibiotic that has antiapoptotic and anti-inflammatory effects in vitro (prevents microglial activation and caspase activation). Minocycline extends survival in mouse models of some neurological conditions, as ALS. ${ }^{109-111}$ Two double-blind, randomized, placebo-controlled phase II clinical trials demonstrated that the drug is safe and well tolerated in 42 ALS patients; ${ }^{23,112}$ however these studies were not powered for efficacy. ${ }^{23} \mathrm{~A}$ recent multicenter, randomized placebo-controlled phase III trial on 412 patients found that minocycline in escalating doses of up to $400 \mathrm{mg} /$ day for nine months has a harmful effect on patients with ALS. A faster ALS-FRS score deterioration and greater mortality (hazard ratio, 1.32; 95\% confidence interval [CI]: 0.83-2.10; $P=0.23$ ) was observed in the minocycline group than in the placebo group. ${ }^{113}$ These results indicate that minocycline is not effective in ALS patients.

\section{$\mathrm{TCH} 346$}

TCH346 is an antiapoptotic agent that binds to glyceraldehyde 3-phosphate dehydrogenase (GAPDH) and blocks the apoptotic pathway in which GAPDH is involved. TCH346 treatment delayed disease onset and slowed the clinical course of the disease in the ALS mouse model. ${ }^{114} \mathrm{~A}$ small sample double-blind placebo-controlled clinical trial conducted on 591 patients from Europe and North America failed to find any beneficial effect of TCH346 given at several dosages on disease progression in patients with ALS. ${ }^{115}$

\section{N-benzyloxycarbonyl-Val-Asp-fluoromethylketone (zVAD-fmk)}

N-benzyloxycarbonyl-Val-Asp-fluoromethylketone (zVAD-fmk) is a broad enzymatic caspase inhibitor. ${ }^{116}$ Intraventricular administration of zVAD-fmk in the late presymptomatic stage significantly delayed disease onset and prolonged survival in SOD1 transgenic mice. ${ }^{116}$ Data on ALS patients are still not available.

\section{Pentoxifylline}

Pentoxifylline is a phosphodiesterase inhibitor that increases cellular cyclic AMP and GMP and demonstrates 
antiapoptotic properties. ${ }^{117}$ A randomized clinical trial conducted on 400 European ALS patients found that treatment with pentoxifylline as add-on to riluzole was not associated with appreciable effect on functional measures. ${ }^{117}$ Moreover, pentoxifylline had a negative effect on survival. At the end of follow-up period, $51.7 \%$ of patients were alive in the pentoxifylline group compared to $59.7 \%$ in the placebo group (unadjusted risk $1.28, P=0.107$; adjusted risk $1.43, P=0.02) .{ }^{117}$

\section{Anti-inflammatory Cyclooxygenase (COX-2) inhibitors}

The enzyme cyclooxygenase-2 (COX-2) has been proposed as an attractive therapeutic target in ALS because its increase in the spinal cord stimulates astrocytic glutamate release. ${ }^{118}$ Elevated levels of COX-2 and prostaglandin $\mathrm{E}_{2}$ have been observed in the spinal cord of SOD1 mutant mice and ALS patients. ${ }^{118}$ Celecoxib, a COX-2 inhibitor has been shown to be beneficial in preclinical testing, prolonging survival of SOD1 mice. ${ }^{119,120}$ A 12-month double-blind placebocontrolled clinical trial was conducted on 300 patients with ALS. Subjects were randomized (with a 2:1 ratio) to receive celecoxib ( $800 \mathrm{mg} /$ day) or placebo for 12 months. ${ }^{121}$ Treatment with celecoxib showed safe results but did not have a beneficial effect on the decline in muscle strength, vital capacity, motor unit number estimates, ALS-FRS score, or survival in patients with ALS. ${ }^{121}$

Nimesulide has been indicated as the preferential COX-2 inhibitor because of has additional antioxidant properties and can be administered via multiple routes, including orally. ${ }^{23}$ Preclinical observations revealed that nimesulide administration decreases prostaglandin $\mathrm{E}_{2}$ levels in the spinal cord of SOD1G93A mice and preserves motor skill integrity. ${ }^{122}$ However, its putative mechanism of action is the same as celecoxib and safety concerns surrounding long-term administration of this medication class may limit the use of COX-2 inhibitors in patients with ALS. ${ }^{23}$ Their combination with other compounds such as creatine is under evaluation. ${ }^{24}$

\section{Glatiramer acetate}

Glatiramer acetate, a combination of four amino acids, is the analogous of myelin basic protein and it is used to reduce the frequency of relapses in patients with multiple sclerosis. ${ }^{20}$ It requires subcutaneous administration and is believed to act by enhancing regulatory T-cell immunity. ${ }^{23,123}$ In addition, it may also have antiglutamatergic and growth factor-stimulating effects. ${ }^{123}$ Results of preclinical studies are limited and conflicting, some studies found that it prolongs survival in SOD1 mutant mice, ${ }^{124}$ while others did not. ${ }^{125}$ In a phase II trial conducted on 20 ALS patients the drug showed safe, well tolerated results and affected the immune system at the dosage studied. ${ }^{126} \mathrm{~A}$ recent large-scale double-blind, randomized placebo-controlled multicenter trial on $366 \mathrm{ALS}$ patients confirmed safety and tolerability of glatiramer acetate at a dose of $40 \mathrm{mg} /$ day but did not show any beneficial effect of the drug on rate of deterioration of the ALS-FRS scale, or time to death, tracheostomy or permanent assisted ventilation. ${ }^{127}$ Further studies are required.

\section{AM- |24I}

Cannabinoids produce anti-inflammatory actions via cannabinoid receptor 1 and 2 (CB2) and delay the progression of neuroinflammation. ${ }^{128} \mathrm{AM}-1241$ is a selective agonist at the CB2 cannabinoid receptors, that are dramatically up-regulated in inflamed neural tissues associated with CNS disorders. ${ }^{128}$ Animal studies on SOD1 mutant mice reported that the injections at symptom onset can dramatically prolong survival. ${ }^{128,129}$ However, there is no experience with this compound on humans and administration is likely to be parenteral. ${ }^{23}$

\section{Celastrol}

Celastrol, a natural product from southern China, has multiple effects that can be relevant to ALS. It exerts potent anti-inflammatory and antioxidative effects, by suppression of tumor necrosis factor- $\alpha$ (TNF- $\alpha$ ), interleukin-1B, and nitric oxide. ${ }^{23}$ It also acts potently to increase expression of heat shock proteins. ${ }^{130}$ The oral administration before the onset of symptoms significantly improved weight loss, motor performance and delayed the onset of ALS in SOD1 transgenic mice. ${ }^{130}$ However, there is a lack of safety and pharmacokinetic data in humans with ALS. ${ }^{23}$

\section{Thalidomide}

Thalidomide, is an historical sedative and now is used again in the treatment of leprosy, myeloma and cachexia. It has a number of interesting mechanisms of action for neurodegenerative disorders such as ALS, including suppression of TNF- $\alpha .{ }^{23}$ When administered orally to SOD1 mutant mice, it enhanced motor performance, decreased motor neuron cell death, and significantly prolonged life span. ${ }^{131}$ However a small open-label study found no improvement in progression of the disease. In addition, treatment with thalidomide was associated with several side effects. ${ }^{132}$ Further clinical trials are however underway. ${ }^{24}$ Because of thalidomide's side effects, lenalidomide may offer a safer alternative. ${ }^{131,133}$ 


\section{Nordihydroguaiaretic acid}

Nordihydroguaiaretic acid Iis a lipoxygenase inhibitor that inhibits TNF- $\alpha$ activation of microglia ${ }^{134}$ and enhances glutamate uptake in motor neuronal cells. ${ }^{135} \mathrm{~A}$ recent animal study on SOD1 transgenic mice found that nordihydroguaiaretic acid extends survival and slowed motor dysfunction. These favorable effects were observed even when administration was begun relatively late in life. ${ }^{134}$ There are still no data on ALS patients.

\section{Pioglitazone}

Pioglitazone is a peroxisome proliferator-activated receptor- $\gamma$ (PPAR- $\gamma$ ) agonist. It is used as an oral antidiabetic, but may also act as potent anti-inflammatory drug. ${ }^{136}$ Three recent animal studies on SOD1 transgenic mice found that the oral administration of pioglitazone significantly improves muscle strength and body weight, delayed the disease onset and prolonged survival. ${ }^{136-138}$ To date, no information on safety and efficacy on ALS patients are available; however, a phase II clinical trial is ongoing. ${ }^{24}$

\section{RO-28-2653}

RO-28-2653 acts as an anti-inflammatory agent by specifically inhibiting the activation of matrix metalloprotease enzymes that digest the extracellular matrix. An increased expression of matrix metalloproteinases and the degradation of the extracellular matrix in postmortem spinal cord tissue have been observed in ALS. ${ }^{139}$ RO-28-2653 prolonged survival in familial ALS mice if given before the onset of symptoms; ${ }^{139}$ however, the administration of the drug at disease onset did not significantly improve survival time. ${ }^{139}$ Despite the unique mechanism of action among ALS relevant therapies, there is a lack of safety or efficacy data for this agent in ALS patients. ${ }^{24}$

\section{ONO-2506}

ONO-2506 is an enantiomeric homolog of valproic acid, which has multiple potential mechanisms for ALS, as antiinflammatory COX-2 inhibitor properties and antiglutamate functions. ${ }^{140} \mathrm{ONO}-2506$ also restores normal astrocytes functions after brain damage and prevents reactive astrocytosis. ${ }^{140}$ European phase I and II studies of 1,200 mg per day oral formulation have been conducted in humans with ALS, but results are not yet available. ${ }^{23,24} \mathrm{~A}$ phase III study has recently been initiated in Europe. ${ }^{140}$

\section{Autophagy inducer}

\section{Lithium}

Both in vitro and in vivo studies revealed that the autophagy pathway is involved during motor neuron death with a protective role. ${ }^{141}$ Lithium is a compound used as a mood stabilizer, which is neuroprotective in a variety of disease models. ${ }^{141}$ At low doses is a well-known autophagy inducer that clears misfolded proteins and altered mitochondria from motor neurons. In addition, lithium preserves mitochondria and sustains their genesis. ${ }^{141}$ Finally, lithium has been reported to decrease glial proliferation in the ALS spinal cord and induces sprouting in cortico-spinal fibers. ${ }^{142}$ Preclinical study on SOD1 transgenic mice found that lithium delayed disease onset and duration and augmented the life span. ${ }^{143}$ These effects were associated with the activation of autophagy, an increase in the number of the mitochondria in motor neurons and suppression of reactive astrogliosis. In a small sample open label study, daily doses of lithium, leading to plasma levels ranging from 0.4 to $0.8 \mathrm{mEq} /$ liter, delayed disease progression in on 44 patients affected by ALS. ${ }^{143}$ Larger clinical trials are ongoing. ${ }^{24}$

\section{Protein aggregation: Histone deacetylase inhibitors and heat-shock protein gene inductors \\ Sodium phenylbutyrate}

Sodium phenylbutyrate improves transcription and posttranscriptional pathways, by inhibiting histone deacetylase enzyme. Transcription dysregulation and consequent abnormal protein aggregation play a role in the pathogenesis of ALS. ${ }^{3}$ Ubiquitin cytosolic inclusions indeed represent one of the pathologic hallmark of ALS. ${ }^{8}$ In the mouse model of ALS sodium phenylbutyrate promoted cell survival, alone or in combination with riluzole. ${ }^{144,145} \mathrm{~A}$ recent 20 -week openlabel study found that the oral administration of sodium phenylbutyrate to 26 ALS patients was safe and tolerable. ${ }^{146}$ Blood histone acetylation levels were significantly increased after sodium phenylbutyrate administration, even at the lowest dosage ( $9 \mathrm{~g}$ /day). ${ }^{146}$ Further animal studies and clinical trials on long-term safety and efficacy are required.

\section{Valproic acid}

Valproic acid is a well-known antiepileptic drug that may modulate transcriptional dysregulation by acting as a histone deacetylase inhibitor. ${ }^{147,148}$ It also may upregulate the antiapoptotic protein Bcl-2. ${ }^{147,148}$ Preclinical studies on SOD1 mutant mice gave discordant results; ${ }^{149-152}$ some studies found that it prolongs survival when given before or at symptoms onset, ${ }^{149,150}$ while others did not. ${ }^{151,152}$ Furthermore, a recent sequential clinical trial found that treatment with valproic acid, at a dose used in epilepsy, is safe but does not show a beneficial effect on survival or disease progression in 163 patients with ALS. ${ }^{153}$ Other clinical trials are underway. ${ }^{24}$ 


\section{Scriptaid}

Scriptaid is a small molecule that acts as a histone deacetylase inhibitor. In vitro studies found that treatment with scriptaid disrupts aggresome formation in cultured cells transfected with mutant SOD1. ${ }^{154}$ Trials on safety and efficacy of this compound both in animal models and ALS patients are still unavailable.

\section{Arimoclomol}

Arimoclomol amplifies heat shock protein gene expression and induces heat-shock protein during cell stress. ${ }^{155}$ This drug may interfere with protein aggregation and apoptosis, mechanisms likely to be involved in ALS pathogenesis. It significantly prolonged survival in SOD1 mice, when administered either before the onset or at the symptoms onset. ${ }^{155,156}$ In a recent early-stage clinical trial it was administered orally at three different dosages to 84 patients with ALS over 12 weeks. ${ }^{157}$ The drug showed safe and well tolerated results at doses up to $300 \mathrm{mg} /$ day ${ }^{157}$ An efficacy study in ALS patients has been planned but is not yet open for recruitment, because the drug has been placed on hold by the FDA until results of preclinical toxicology studies become available. ${ }^{158}$

\section{Discussion}

ALS remains a devastating disease that dramatically reduces quality of life and survival of patients, despite in recent years advances in understanding the mechanisms of ALS have been provided by the development of animal models of ALS and a large number of drugs have been tested.

The management of ALS patients is still supportive and symptoms-based and, actually, riluzole is the only compound that demonstrated a beneficial effect on ALS patients, but with only modest increase in survival. Although several drugs (such as creatine, celecoxib, IGF-1, CNF, gabapentin, topiramate, lamotrigine, minocycline, thalidomide, valproate, vitamin E) gave positive results in preclinical animal studies, none of these compounds, when tested in humans, significantly prolonged survival or improved quality of life of ALS patients.

Several factors have been implicated in the explaining the predominantly negative results of numerous randomized clinical trials in ALS, including methodological problems in the use of animal-drug screening, the lack of assessment of pharmacokinetic profile of the drugs and methodological pitfalls of clinical trials.

\section{Use of animal-drug screening}

The therapeutic successes obtained in the SOD1 ALS rodent model has not translated into effective therapy for
ALS patients. Riluzole, the only effective drug in ALS, was developed without the use of the SOD1 transgenic mice model. ${ }^{158}$ Based on these observations, the utility of animal models in the preclinical phase for identifying therapeutic agents in ALS has been doubted. ${ }^{23,103}$

Several possible explanations are conceivable for the discrepancy between successful animal studies and ineffective clinical trials in humans. First, most of the available therapeutic trials for ALS conducted on mice model present several methodological pitfalls, as pointed out by recent metaanalyses. ${ }^{103,159}$ First, the lack of control in most of the studies for critical biological confounding variables, including sex, that should be ruled out when designing and interpreting results from efficacy studies. ${ }^{103,159} \mathrm{~A}$ second explanation could be that treatment has been started before the onset of symptoms in more than $80 \%$ of the studies. ${ }^{103}$ Although this approach may be more effective in showing a delay in the onset or slowing in the progression of the disease, it cannot be used in patients with sporadic ALS, as to date subjects who are at high risk for developing ALS cannot be identified. Third, only the minority of studies was randomized and investigators were blinded in an even smaller number. ${ }^{103}$

Furthermore, the intra-species differences in pharmacokinetics, difficulties in establishing dose equivalence to obtain in humans a biologic activity similar to that observed in mice, the difference between laboratories in the design of the animal study, may also concur to explain the contrast between results of preclinical studies and ALS clinical trials. ${ }^{8,23,103}$

Established consensus guidelines have been therefore advocated to ensure that ALS animal drug studies are conducted in a uniform manner. ${ }^{23}$ With this objective, a recent study established several parameters for optimal study design in the SOD1 transgenic mouse model. ${ }^{159}$ Using these new study design criteria several compounds (minocycline, creatine, celecoxib, sodium phenylbutyrate, ceftriaxone, thalidomide, and riluzole) were retested and no benefit on survival was found for any compounds, including riluzole. ${ }^{159}$

Finally, another possible explanation for the contrast between results of preclinical studies and ALS clinical trials may be that the current mouse model of familial ALS is not able to evaluate the drug effect in patients with sporadic ALS. Animal drug-screening studies in ALS almost exclusively utilized the mutant SOD1 (G93A) mouse, but it remains to be firmly demonstrated that the SOD1 transgenic mouse models are an accurate and useful model for sporadic ALS. ${ }^{103,159}$ The role of biochemically altered SOD1 in sporadic ALS remains speculative and some pathogenetic mechanisms are different between familial and sporadic ALS. ${ }^{3}$ Alternative models that better 
represent pathological features observed in sporadic ALS should be therefore obtained. ${ }^{23}$ However, until a model of sporadic ALS will be developed, a possible strategy will be to require multiple preclinical information both from in vitro and in vivo studies before the start of clinical trials on ALS patients.

\section{Correct assessment of pharmacokinetic profile}

There has been a tendency for potentially beneficial candidates to move rapidly to large ALS clinical trials, before an adequate assessment of parameters as the pharmacokinetic profile, the safety/toxicity properties. Dose-ranging studies are a prerequisite to phase III studies to determine the most effective and safe dosage.$^{23}$ This is particularly relevant if we consider that the tolerability of a dose in healthy patients may not be taken as indication that the same dose will be safe in patients with ALS. In the clinical trial of topiramate in ALS, the frequency of adverse events was higher in patients with ALS compared to that observed in patients with epilepsy, ${ }^{34}$ probably relating to the dehydration and malnutrition in patients with ALS. Finally, the lack of ability of a drug to cross the human blood-brain barrier may not represent an important issue for the efficacy of newly developed drugs in ALS. Recent studies indeed found that blood-brain barrier is compromised in the areas of motor neuron degeneration of ALS mouse models and that tight junction proteins are down-regulated in ALS patients. ${ }^{160,161}$

\section{Methodological pitfalls of ALS clinical trials}

Several methodological pitfalls have been underlined in the design of most of ALS clinical trials, including the small sample size, the inclusion of heterogeneous populations, the short follow-up, and the use of inadequate efficacy measures. The small sample size is believed to prevent the assessment of mild/moderate drug effects, as we may expect in ALS. ${ }^{162}$

The inclusion of patients with variable disease duration, site of onset (bulbar vs spinal), values of forced vital capacity may represent a remarkable source of bias. ${ }^{162}$ The enrolment of ALS of newly diagnosed cases from population-based cohorts has been proposed to test the efficacy of new pharmaceutical compounds, because an early start of treatment is an important issue in evaluating efficacy for devastating disease, such as ALS. ${ }^{162}$ Population-based cohorts may offer the advantages of a greater potential response to a given treatment, when compared to prevalent cohorts with long-lasting disease, as observed by studies conducted on riluzole. ${ }^{10,11}$ Moreover, a rigorous control of confounding factors is necessary in ALS clinical trials, given the presence of prognostic indicators that may significantly affect the primary end-points of the study.

The study end-points are an important issue for the choice of the study design. A wide range of end-points have been included, from death or tracheostomy, gastrostomy, mechanical ventilation, and a number of disability measures, like ALSFRS. ${ }^{23}$ Another crucial point is the short duration (6-12 months) of the large majority of clinical trials; this is an important issue to evaluate the efficacy at the late stage of the disease. ${ }^{10,11}$

\section{Comments}

We believe that the development of more potent riluzole analogs should be an important issue in the near future, as riluzole is the only therapy to date that slows disease progression in patients with ALS. ${ }^{6}$

Until this is confirmed, the use of a single medication that targets more than one pathogenic pathway or combining agents with different mechanisms of action could represent a therapeutic approach to the disease. Although multiple drug interactions might hypothetically increase the incidence of side effects, such combination therapy may be successful, as observed in oncology. ${ }^{23}$

Clinical trials including "cocktail therapies" should also be designed using new drugs as add-on therapies to riluzole. ${ }^{23}$ Preclinical studies in SOD1 transgenic mice indicated that therapy combinations are more effective than individual agents. ${ }^{119,144}$ This approach has recently been considered in a phase II clinical trial and it appeared feasible, efficient, and has been demonstrated some beneficial effect on ALS patients. ${ }^{89}$ Furthermore, important news should be provided in the next years by research focused on drug delivery via viral vectors or compounds interfering with transcriptional dysregulation, protein aggregation, and diseasecausing mutations. Thus, results from ongoing trials of phenylbutyrate (which may reverse transcriptional dysregulation) and arimoclomol (which may mediate protein aggregation) will provide important information for everyday clinical practice.

\section{Disclosures}

The authors report no conflicts of interest in this work.

\section{References}

1. Rowland LP, Shneider NA. Amyotrophic lateral sclerosis. $N$ Engl J Med. 2001;344:1688-1700.

2. Goodall EF, Morrison KE. Amyotrophic lateral sclerosis (motor neuron disease): proposed mechanisms and pathways to treatment. Expert Rev Mol Med. 2006;8:1-22.

3. Rothstein JD. Current hypotheses for the underlying biology of amyotrophic lateral sclerosis. Ann Neurol. 2009;65(Suppl):S3-S9. 
4. Pioro EP, Mitsumoto H. Animal models of ALS. Clin Neurosci. 1995-1996;3(6):375-385.

5. Bruijn LI, Miller TM, Cleveland DW. Unraveling the mechanisms involved in motor neuron degeneration in ALS. Annu Rev Neurosci. 2004;27:723-749.

6. Miller RG, Mitchell JD, Lyon M, Moore DH. Riluzole for amyotrophic lateral sclerosis (ALS)/motor neuron disease (MND). Cochrane Database Syst Rev. 2007;1:CD001447.

7. Mitchell JD, Borasio GD. Amyotrophic lateral sclerosis. Lancet. 2007;369:2031-2041.

8. Traynor BJ, Bruijn L, Conwit R, et al. Neuroprotective agents for clinical trials in ALS: a systematic assessment. Neurology. 2006;67:20-27.

9. Gurney ME, Fleck TJ, Himes CS, Hall ED. Riluzole preserves motor function in a transgenic model of familial amyotrophic lateral sclerosis. Neurology. 1998;50:62-66.

10. Traynor BJ, Alexander M, Corr B, Frost E, Hardiman O. An outcome study of riluzole in amyotrophic lateral sclerosis. A population based study in Ireland, 1996-2000. J Neurol. 2003;250:473-479.

11. Zoccolella S, Beghi E, Palagano G, et al. Riluzole and amyotrophic lateral sclerosis survival: a population-based study in southern Italy. Eur J Neurol. 2007;14:262-268.

12. Dunlop J, Beal McIlvain H, Yijin S, Howland DS. Impaired spinal cord glutamate transport capacity and reduced sensitivity to Riluzole in a transgenic superoxidedismutase mutant rat model of amyotrophic lateral sclerosis. J Neurosci. 2003;23:1688-1696.

13. Chen HS, Pellegrini JW, Aggarwal SK, et al. Open-channel block of N-methyl-D-aspartate (NMDA) responses by memantine: therapeutic advantage against NMDA receptor-mediated neurotoxicity. J Neurosci. 1992;12:4427-4436.

14. Volbracht C, van Beek J, Zhu C, Blomgren K, Leist M. Neuroprotective properties of memantine in different in vitro and in vivo models of excitotoxicity. Eur J Neurosci. 2006;23:2611-2622.

15. Reisberg G, Doody R, Stoffler A, Schmitt F, Ferris S, Mobius HJ; Memantine Study Group. Memantine in moderate-to-severe Alzheimer's disease. N Engl J Med. 2003;348:1333-1341.

16. Wang R, Zhang D. Memantine prolongs survival in an amyotrophic lateral sclerosis mouse model. Eur J Neurosci. 2005;22:2376-2380.

17. Joo IS, Hwang DH, Seok JI, Shin SK, Kim SU. Oral administration of memantine prolongs survival in a transgenic mouse model of amyotrophic lateral sclerosis. J Clin Neurol. 2007;3:181-186.

18. ALS Association. Clinical trials. Available from: http://www.alsa. org/patient/drug.cfm. Accessed on October 10, 2009.

19. Lee J, Ryu H, Kowall NW. Motor neuronal protection by L-arginine prolongs survival of mutant SOD1 (G93A) ALS mice. Biochem Biophys Res Commun. 2009;384:524-529.

20. Iłzecka J, Stelmasiak Z, Solski J, Wawrzycki S, Szpetnar M. Plasma amino acids concentration in amyotrophic lateral sclerosis patients. Amino Acids. 2003;25(1):69-73.

21. Rothstein JD, Patel S, Regan MR, et al. Beta-lactam antibiotics offer neuroprotection by increasing glutamate transporter expression. Nature. 2005;433:73-77.

22. Ji HF, Shen L, Zhang HY. Beta-lactam antibiotics are multipotent agents to combat neurological diseases. Biochem Biophys Res Commun. 2005;333:661-663.

23. Bedlack RS, Traynor BJ, Cudkowicz ME. Emerging disease-modifying therapies for the treatment of motor neuron disease/amyotropic lateral sclerosis. Expert Opin Emerg Drugs. 2007;12:229-252.

24. Clinical Trials. Clinical trial ceftriaxone in subjects with ALS. July 21, 2009. Available from: http://clinicaltrials.gov/ct2/show/NCT00349622. Accessed on October 10, 2009.

25. Akaike A, Tamura Y, Sato Y, Yokota T. Protective effects of a vitamin B12 analog, methylcobalamin, against glutamate cytotoxicity in cultured cortical neurons. Eur J Pharmacol. 1993;241:1-6.

26. Zhang X, Chen S, Li L, Wang Q, Le W. Folic acid protects motor neurons against the increased homocysteine, inflammation and apoptosis in SOD1(G93A) transgenic mice. Neuropharmacology. 2008;54: $1112-1119$.
27. Lee KW, Park JH, Kim MY, et al. Neuroprotective effects of multi-vitamin therapy in a transgenic mouse model of amyotrophic lateral sclerosis [abstract]. Amyotroph Lat Scler. 2006;7(Supp1 1): 122-123.

28. Kaji R, Kodama M, Imamura A, et al. Effect of ultrahigh-dose methylcobalamin on compound muscle action potentials in amyotrophic lateral sclerosis: a double-blind controlled study. Muscle Nerve. 1998;21:1775-1778.

29. Izumi Y, Kaji R. Clinical trials of ultra-high-dose methylcobalamin in ALS. Brain Nerve. 2007;59:1141-1147.

30. Thomas AG, Wozniak KM, Tsukamoto T, et al. Glutamate carboxypeptidase II (NAALADase) inhibition as a novel therapeutic strategy. Adv Exp Med Biol. 2006;576:327-337.

31. Ghadge GD, Slusher BS, Bodner A, et al. Glutamate carboxypeptidase II inhibition protects motor neurons from death in familial amyotrophic lateral sclerosis models. Proc Natl Acad Sci U S A. 2003;100(16):9554-9959.

32. Maragakis NJ, Jackson M, Ganel R, Rothstein JD. Topiramate protects against motor neuron degeneration in organotypic spinal cord cultures but not in G93A SOD1 transgenic mice. Neurosci Lett. 2003;338(2):107-110.

33. Cudkowicz ME, Shefner JM, Schoenfeld DA, et al. A randomized, placebo-controlled trial of topiramate in amyotrophic lateral sclerosis. Neurology. 2003;61(4):456-464.

34. Miller RG, Moore DH 2nd, Gelinas DF, et al. Phase III randomized trial of gabapentin in patients with amyotrophic lateral sclerosis. Neurology. 2001;56(7):843-848.

35. Gurney ME, Cutting FB, Zhai P, et al. Benefit of vitamin E, riluzole, and gabapentin in a transgenic model of familial amyotrophic lateral sclerosis. Ann Neurol. 1996;39:147-157.

36. Miller RG, Moore D, Young LA, et al; Placebo-controlled trial of gabapentin in patients with amyotrophic lateral sclerosis. WALS Study Group. Western Amyotrophic Lateral Sclerosis Study Group. Neurology. 1996;47:1383-1388.

37. Kalra S, Cashman NR, Caramanos Z, Genge A, Arnold DL. Gabapentin therapy for amyotrophic lateral sclerosis: lack of improvement in neuronal integrity shown by MR spectroscopy. AJNR Am J Neuroradiol. 2003;24(3):476-480

38. Casanovas A, Ribera J, Hukkanen M, et al. Prevention by lamotrigine, MK-801 and N omega-nitro-1-arginine methyl ester of motoneuron cell death after neonatal axotomy. Neuroscience. 1996;71:313-325.

39. Eisen A, Stewart H, Schulzer M, Cameron D. Anti-glutamate therapy in amyotrophic lateral sclerosis: a trial using lamotrigine. Can J Neurol Sci. 1993;20:297-301.

40. Ryberg H, Askmark H, Persson LI. A double-blind randomized clinical trial in amyotrophic lateral sclerosis using lamotrigine: effects on CSF glutamate, aspartate, branched-chain amino acid levels and clinical parameters. Acta Neurol Scand. 2003;108:1-8.

41. Sakowski SA, Schuyler AD, Feldman EL. Insulin-like growth factor-I for the treatment of amyotrophic lateral sclerosis. Amyotroph Lateral Scler. 2009;10:63-73.

42. Lai EC, Felice KJ, Festoff BW, et al; Effect of recombinant human insulin-like growth factor-I on progression of ALS. A placebocontrolled study. The North America ALS/IGF-I Study Group. Neurology. 1997;49:1621-1630.

43. Borasio GD, Robberecht W, Leigh PN, et al; A placebo-controlled trial of insulin-like growth factor-I in amyotrophic lateral sclerosis. European ALS/IGF-I Study Group. Neurology. 1998;51: 583-586.

44. Sorenson EJ, Windbank AJ, Mandrekar JN, et al. Subcutaneous IGF-1 is not beneficial in 2-year ALS trial. Neurology. 2008;71:1770-1775.

45. Mitchell JD, Wokke JHJ, Borasio GD. Recombinant human insulin-like growth factor I (rhIGF-I) for amyotrophic lateral sclerosis/motor neuron disease. Cochrane Database Syst Rev. 2007;4:CD002064.

46. Dodge JC, Haidet AM, Yang W, et al. Delivery of AAV-IGF-1 to the CNS extends survival in ALS mice through modification of aberrant glial cell activity. Mol Ther. 2008;16:1056-1064. 
47. Riddoch-Contreras J, Yang SY, Dick JR, Goldspink G, Orrell RW, Greensmith L. Mechano-growth factor, an IGF-I splice variant, rescues motoneurons and improves muscle function in SOD1(G93A) mice. Exp Neurol. 2009;215:281-289.

48. DeChiara TM, Vejsada R, Poueymirou WT, et al. Mice lacking the CNTF receptor, unlike mice lacking CNTF, exhibit profound motor neuron deficits at birth. Cell. 1995;83:313-322.

49. Laaksovirta H, Soinila S, Hukkanen V, Röyttä M, Soilu-Hänninen M. Serum level of CNTF is elevated in patients with amyotrophic lateral sclerosis and correlates with site of disease onset. Eur J Neurol. 2008; 15:355-359.

50. ALS CNTF Treatment Study Group. A double-blind placebo-controlled clinical trial of subcutaneous recombinant human ciliary neurotrophic factor (rHCNTF) in amyotrophic lateral sclerosis. ALS CNTF Treatment Study Group. Neurology. 1996;46:1244-1249.

51. Miller RG, Petajan JH, Bryan WW, et al; A placebo-controlled trial of recombinant human ciliary neurotrophic (rhCNTF) factor in amyotrophic lateral sclerosis. rhCNTF ALS Study Group. Ann Neurol. 1996;39:256-260.

52. Bongioanni P, Reali C, Sogos V. Ciliary neurotrophic factor (CNTF) for amyotrophic lateralsclerosis or motor neuron disease. Cochrane Database Syst Rev. 2004;3:CD004302.

53. Malhotra S, Nijhawan S, Rosenbaum DM. Erythropoietin (epoetin) as a protective factor for the brain. Curr Atheroscler Rep. 2004;6:301-306.

54. Kim S, Kim H, Koh S, et al. Effectiveness of recombinant human erythropoietin therapy in amyotrophic lateral sclerosis [abstract]. Amyotroph Lateral Scler. 2006;7(Suppl 1):9.

55. Caldiroli D, Ghelma F, Ferrara G, Ghezzi P, Mantegazza R. Erythropoietin in amyotrophic lateral sclerosis: A pilot, randomized, double-blind, placebocontrolled study of safety and tolerability. Neuromuscular Diseases Unit Amyotroph Lateral Scler. 2009 May; 29:1-6. [Epub ahead of print]

56. Zheng C, Sköld MK, Li J, Nennesmo I, Fadeel B, Henter JI. VEGF reduces astrogliosis and preserves neuromuscular junctions in ALS transgenic mice. Biochem Biophys Res Commun. 2007;363:989-993.

57. Tovar-Y-Romo LB, Zepeda A, Tapia R. Vascular endothelial growth factor prevents paralysis and motoneuron death in a rat model of excitotoxic spinal cord neurodegeneration. J Neuropathol Exp Neurol. 2007;66:913-922.

58. Bogaert E, Van Damme P, Poesen K, et al. VEGF protects motor neurons against excitotoxicity by upregulation of GluR2. Neurobiol Aging. 2009; Jan 28. [Epub ahead of print].

59. Hwang DH, Lee HJ, Park IH, et al. Intratechal transplantation of human neural stem cells overexpressing VEGF provide behavioral improvement, disease onset delay and survival extension in transgenic ALS mice. Gene Ther. 2009 Jul 23. [Epub ahead of print].

60. Pitzer C, Krüger C, Plaas C, et al. Granulocyte-colony stimulating factor improves outcome in a mouse model of amyotrophic lateral sclerosis. Brain. 2008;131:3335-3347.

61. Cashman N, Tan LY, Krieger C, Mädler B, et al; Pilot study of granulocyte colony stimulating factor (G-CSF)-mobilized peripheral blood stem cells in amyotrophic lateral sclerosis (ALS). Muscle Nerve. 2008;37:620-625.

62. Nefussy B, Artamonov I, Deutsch V, Naparstek E, Nagler A, Drory VE; Recombinant human granulocyte-colony stimulating factor administration for treating amyotrophic lateral sclerosis: A pilot study. Amyotroph Lateral Scler. 2009 May; 15:1-7. [Epub ahead of print].

63. Aoki M, Ishigaki I, Nagai M, et al. Intrathecal delivery of hepatocyte growth factor at the onset of paralysis slows disease progression in a rat model of ALS [abstract]. Amyotroph Lateral Scler. 2006;7(Suppl 1):41.

64. Kadoyama K, Funakoshi H, Ohya W, Nakamura T. Hepatocyte growth factor (HGF) attenuates gliosis and motoneuronal degeneration in the brainstem motor nuclei of a transgenic mouse model of ALS. Neurosci Res. 2007;59:446-456.

65. Sun W, Funakoshi H, Nakamura T. Overexpression of HGF retards disease progression and prolongs life span in a transgenic mouse model of ALS. J Neurosci. 2002;22:6537-6548.
66. Kato S, Funakoshi H, Nakamura T, et al. Expression of hepatocyte growth factor and c-Met in the anterior horn cells of the spinal cord in the patients with amyotrophic lateral sclerosis (ALS): immunohistochemical studies on sporadic ALS and familial ALS with superoxide dismutase 1 gene mutation. Acta Neuropathol. 2003;106:112-120.

67. Ochs G, Penn RD, York M, et al. A phase I/II trial of recombinant methionyl human brain derived neurotrophic factor administered by intrathecal infusion to patients with amyotrophic lateral sclerosis. Amyotroph Lateral Scler Other Motor Neuron Disord. 2000;1:201-206.

68. Mitsumoto H, Ikeda K, Klinkosz B, Cedarbaum JM, Wong V, Lindsay RM. Arrest of motor neuron disease in wobbler mice cotreated with CNTF and BDNF. Science. 1994;265:1107-1110.

69. Ikeda K, Klinkosz B, Greene T, et al. Effects of brain-derived neurotrophic factor on motor dysfunction in wobbler mouse motor neuron disease. Ann Neurol. 1995;37:505-511.

70. Bradley WG; A phase I/II study of recombinant brain-derived neurotrophic in patients with ALS. Ann Neurol. 1995;38:971.

71. BDNF Group; A controlled trial of recombinant methionyl human BDNF in ALS: The BDNF Study Group (Phase III). Neurology. 1999;52:1427-1433.

72. Acsadi G, Anguelov RA, Yang H, et al. Increased survival and function of SOD1 mice after glial cell-derived neurotrophic factor gene therapy. Hum Gene Ther. 2002;13:1047-1059.

73. Manabe Y, Nagano I, Gazi MS, et al. Adenovirus-mediated gene transfer of glial cell line-derived neurotrophic factor prevents motor neuron loss of transgenic model mice for amyotrophic lateral sclerosis. Apoptosis. 2002;7:329-334.

74. Wang LJ, Lu YY, Muramatsu S, Ikeguchi K, et al. Neuroprotective effects of glial cell line-derived neurotrophic factor mediated by an adeno-associated virus vector in a transgenic animal model of amyotrophic lateral sclerosis. J Neurosci. 2002;22:6920-6928.

75. Suzuki M, McHugh J, Tork C, et al. Direct muscle delivery of GDNF with human mesenchymal stem cells improves motor neuron survival and function in a rat model of familial ALS. Mol Ther. 2008;16:2002-2010.

76. Suzuki M, McHugh J, Tork C, et al. GDNF secreting human neural progenitor cells protect dying motor neurons, but not their projection to muscle, in a rat model of familial ALS. PLoS One. 2007;2(1):e689.

77. Grundström E, Lindholm D, Johansson A, Blennow K, Askmark H. GDNF but not BDNF is increased in cerebrospinal fluid in amyotrophic lateral sclerosis. Neuroreport. 2000;11:1781-1783.

78. Jiang YM, Yamamoto M, Kobayashi Y, et al. Gene expression profile of spinal motor neurons in sporadic amyotrophic lateral sclerosis. Ann Neurol. 2005;57:236-251.

79. Lacomblez L, Bensimon G, Douillet P, Doppler V, Salachas F, Meininger V. Xaliproden in amyotrophic lateral sclerosis: early clinical trials. Amyotroph Lateral Scler Other Motor Neuron Disord. 2004;5:99-106.

80. Meininger V, Bensimon G, Bradley WR, et al. Efficacy and safety of xaliproden in amyotrophic lateral sclerosis: results of two phase III trials. Amyotroph Lateral Scler. 2004;5:107-117.

81. Matthews RT, Yang L, Browne S, Baik M, Beal MF. Coenzyme Q10 administration increases brain mitochondrial concentrations and exerts neuroprotective effects. Proc Natl Acad Sci U SA. 1998;95:8892-8897.

82. Ferrante KL, Shefner J, Zhang H, et al. Tolerance of high-dose (3,000 mg/day) coenzyme Q10 in ALS. Neurology. 2005;65: 1834-1836.

83. Levy G, Kaufmann P, Buchsbaum R, et al. A two-stage design for a phase II clinical trial of coenzyme Q10 in ALS. Neurology. 2006;66:660-663.

84. Rothstein J. Of mice and men: reconciling preclinical ALS mouse studies and human clinical trials. Ann Neurol. 2003;53:423-426.

85. Groeneveld GJ, Veldink JH, van der Tweel I, et al. A randomized sequential trial of creatine in amyotrophic lateral sclerosis. Ann Neurol. 2003;53:437-445.

86. Shefner JM, Cudkowicz ME, Schoenfeld D, et al. A clinical trial of creatine in ALS. Neurology. 2004;63:1656-1661. 
87. Rosenfeld J, King RM, Jackson CE, et al. Creatine monohydrate in ALS: effects on strength, fatigue, respiratory status and ALSFRS. Amyotroph Lateral Scler. 2008;9:266-272.

88. Mazzini L, Balzarini C, Colombo R, et al. Effects of creatine supplementation on exercise performance and muscular strength in amyotrophic lateral sclerosis: preliminary results. J Neurol Sci. 2001;191:139-144.

89. Zhang W, Narayanan M, Friedlander RM. Additive neuroprotective effects of minocycline with creatine in a mouse model of ALS. Ann Neurol. 2003;53:267-270.

90. Gordon PH, Cheung YK, Levin B, et al. A novel, efficient, randomized selection trial comparing combinations of drug therapy for ALS. Amyotroph Lateral Scler. 2008;9:212-222.

91. Desnuelle C, Dib M, Garrel C, Favier A. A double-blind, placebocontrolled trial of a-tocopherol (vitamin E) in the treatment of amyotrophic lateral sclerosis. Amyotroph Lateral Scler Other Motor Neuron Disord. 2001;2:9-18.

92. Graf M, Ecker D, Horowski R, et al. High dose vitamin E therapy in amyotrophic lateral sclerosis as add-on therapy to riluzole: results of a placebo-controlled double-blind study. J Neural Transm. 2005;112:649-660.

93. Veldink JH, Kalmijn S, Groeneveld GJ, et al. Intake of polyunsaturated fatty acids and vitamin E reduces the risk of developing amyotrophic lateral sclerosis. J Neurol Neurosurg Psychiatry. 2007;78:367-371.

94. Ito H, Wate $\mathrm{R}$, Zhang J, et al. Treatment with edaravone, initiated at symptom onset, slows motor decline and decreases SOD1 deposition in ALS mice. Exp Neurol. 2008;213:448-455.

95. Yoshino H, Kimura A. Investigation of the therapeutic effects of edaravone, a free radical scavenger, on amyotrophic lateral sclerosis (Phase II study). Amyotroph Lateral Scler. 2006;7:241-245.

96. Pattee GL, Post GR, Gerber RE, Bennett JP Jr. Reduction of oxidative stress in amyotrophic lateral sclerosis following pramipexole treatment. Amyotroph Lateral Scler Other Motor Neuron Disord. 2003;4:90-95.

97. Wang H, Larriviere KS, Keller KE, et al. R+ pramipexole as a mitochondrially focused neuroprotectant: initial early phase studies in ALS. Amyotroph Lateral Scler. 2008;9:50-58.

98. Gribkoff VK, Bozik ME. KNS-760704 [(6R)-4,5,6,7-tetrahydroN6-propyl-2, 6-benzothiazole-diamine dihydrochloride monohydrate] for the treatment of amyotrophic lateral sclerosis. CNS Neurosci Ther. 2008;14:215-226.

99. Orrell RW. AEOL-10150 (Aeolus). Curr Opin Investig Drugs. 2006;7:70-80.

100. Petri S, Kiaei M, Kipiani K, et al. Additive neuroprotective effects of a histone deacetylase inhibitor and a catalytic antioxidant in a transgenic mouse model of amyotrophic lateral sclerosis. Neurobiol Dis. 2006;22:40-49.

101. Crow JP, Calingasan NY, Chen J, Hill JL, Beal MF. Manganese porphyrin given at symptom onset markedly extends survival of ALS mice. Ann Neurol. 2005;58:258-265.

102. AEOLUS Pharmaceuticals. Website. 2006. Available from: http:// www.aeoluspharma.com/AEOL10150dev.php. Accessed on October 10, 2009.

103. Benatar M. Lost in translation: treatment trials in the SOD1 mouse and in human ALS. Neurobiol Dis. 2007;26(1):1-13.

104. Tokuda E, Ono S, Ishige K, et al. Ammonium tetrathiomolybdate delays onset, prolongs survival, and slows progression of disease in a mouse model for amyotrophic lateral sclerosis. Exp Neurol. 2008;213:122-128.

105. Andreassen OA, Dedeoglu A, Klivenyi P, Beal MF, Bush AI. $\mathrm{N}$-acetyl-L-cysteine improves survival and preserves motor performance in an animal model of familial amyotrophic lateral sclerosis. Neuroreport. 2000;11:2491-2493.

106. Louwerse ES, Weverling GJ, Bossuyt PM, Meyjes FE, de Jong JM. Randomized, double-blind, controlled trial of acetylcysteine in amyotrophic lateral sclerosis. Arch Neurol. 1995;52:559-564.
107. Bordet T, Buisson B, Michaud M, et al. Identification and characterization of cholest-4-en-3-one, oxime (TRO19622), a novel drug candidate for amyotrophic lateral sclerosis. J Pharmacol Exp Ther. 2007;322:709-720.

108. Brooks B, Sanajak M, Roelke K, et al. Phase 2B randomized dose-ranging clinical trial of tamoxifen, a selective estrogen receptor modulator (SERM), in amyotrophic lateral scelrosis (ALS): sensitivity analyses of discordance between survival and functional outcomes with long-term follow-up. Amyotroph Lateral Scler. 2005;6(Suppl 1):118.

109. Kriz J, Nguyen MD, Julien JP. Minocycline slows disease progression in a mouse model of amyotrophic lateral sclerosis. Neurobiol Dis. 2002;10:268-278.

110. Zhu S, Stavrovskaya IG, Drozda M, et al. Minocycline inhibits cytochrome c release and delays progression of amyotrophic lateral sclerosis in mice. Nature. 2002;417:74-78.

111. Van Den BL, Tilkin P, Lemmens G, Robberecht W. Minocycline delays disease onset and mortality in a transgenic model of ALS. Neuroreport. 2002; $13: 1067-1070$

112. Gordon PH, Moore DH, Gelinas DF, et al. Placebo-controlled phase I/II studies of minocycline in amyotrophic lateral sclerosis. Neurology. 2004;62:1845-1847.

113. Gordon PH, Moore DH, Miller RG, et al. Efficacy of minocycline in patients with amyotrophic lateral sclerosis: a phase III randomised trial. Lancet Neurol. 2007;6:1045-1053.

114. Sagot Y, Toni N, Perrelet D, et al. An orally active anti-apoptotic molecule (CGP 3466B) preserves mitochondria and enhances survival in an animal model of motorneuron disease. Br J Pharmacol. 2000;131:721-728.

115. Miller R, Bradley W, Cudkowicz M, et al. Phase II/III randomized trial of TCH346 in patients with ALS. Neurology. 2007;69:776-784.

116. Li M, Ona VO, Guégan C, et al. Functional role of caspase-1 and caspase-3 in an ALS transgenic mouse model. Science. 2000;288(5464):335-339.

117. Meininger V, Asselain B, Guillet P, et al. Pentoxifylline in ALS: a double-blind, randomized, multicenter, placebo-controlled trial. Neurology. 2006;66:88-92.

118. Almer G, Guegan C, Teismann P, et al. Increased expression of the pro-inflammatory enzyme cyclooxygenase-2 in amyotrophic lateral sclerosis. Ann Neurol. 2001;49:176-185.

119. Klivenyi P, Kiaei M, Gardian G, Calingasan NY, Beal MF. Additive neuroprotective effects of creatine and cyclooxygenase 2 inhibitors in a transgenic mouse model of amyotrophic lateral sclerosis. JNeurochem. 2004;88:576-582.

120. Drachman DB, Frank K, Dykes-Hoberg M, et al. Cyclooxygenase 2 inhibition protects motor neurons and prolongs survival in a transgenic mouse model of ALS. Ann Neurol. 2002;52:771-778.

121. Cudkowicz ME, Shefner JM, Schoenfeld DA, et al. Trial of celecoxib in amyotrophic lateral sclerosis. Ann Neurol. 2006;60:22-31.

122. Pompl PN, Ho L, Bianchi M, McManus T, Qin W, Pasinetti GM. A therapeutic role for cyclooxygenase-2 inhibitors in a transgenic mouse model of amyotrophic lateral sclerosis. FASEB J. 2003;17:725-727.

123. Blair M, Pease ME, Hammond J, et al. Effect of glatiramer acetate on primary and secondary degeneration of retinal ganglion cells in the rat. Invest Ophthalmol Vis Sci. 2005;46:884-890.

124. Banerjee R, Mosley RL, Reynolds AD, et al. Adaptive immune neuroprotection in G93A-SOD1 amyotrophic lateral sclerosis mice. PLoS One. 2008;3(7):e2740.

125. Haenggeli C, Julien JP, Mosley RL, et al. Therapeutic immunization with a glatiramer acetate derivative does not alter survival in G93A and G37R SOD1 mouse models of familial ALS. Neurobiol Dis. 2007;26:146-152.

126. Gordon PH, Doorish C, Montes J, et al. Randomized controlled phase II trial of glatiramer acetate in ALS. Neurology. 2006;67:920.

127. Meininger V, Drory VE, Leigh PN, Ludolph A, Robberecht W, Silani V. Glatiramer acetate has no impact on disease progression in ALS at $40 \mathrm{mg} /$ day: A double-blind, randomized, multicentre, placebo-controlled trial. Amyotroph Lateral Scler. 2009 May 1:1-7. [Epub ahead of print]. 
128. Shoemaker JL, Seely KA, Reed RL, Crow JP, Prather PL. The CB2 cannabinoid agonist AM-1241 prolongs survival in a transgenic mouse model of amyotrophic lateral sclerosis when initiated at symptom onset. J Neurochem. 2007;101:87-98.

129. Kim K, Moore DH, Makriyannis A, Abood ME. AM1241, a cannabinoid CB2 receptor selective compound, delays disease progression in a mouse model of amyotrophic lateral sclerosis. Eur J Pharmacol. 2006;542:100-105.

130. Kiaei M, Kipiani K, Petri S, Chen J, Calingasan NY, Beal MF. Celastrol blocks neuronal cell death and extends life in transgenic mouse model of amyotrophic lateral sclerosis. Neurodegener Dis. 2005;2:246-254.

131. Kiaei M, Petri S, Kipiani K, et al. Thalidomide and lenalidomide extend survival in a transgenic mouse model of amyotrophic lateral sclerosis. J Neurosci. 2006;26:2467-2473.

132. Stommel EW, Cohen JA, Fadul CE, et al. Efficacy of thalidomide for the treatment of amyotrophic lateral sclerosis: A phase II open label clinical trial. Amyotroph Lateral Scler. 2009 Jan 28:1-12. [Epub ahead of print].

133. List A, Kurtin S, Roe DJ, et al. Efficacy of lenalidomide in myelodysplastic syndromes. N Engl J Med. 2005;352:549-557.

134. West M, Mhatre M, Ceballos A, et al. The arachidonic acid 5-lipoxygenase inhibitor nordihydroguaiaretic acid inhibits tumor necrosis factor alpha activation of microglia and extends survival of G93A-SOD1 transgenic mice. J Neurochem. 2004;91:133-143.

135. Boston-Howes W, Williams EO, Bogush A, Scolere M, Pasinelli P, Trotti D. Nordihydroguaiaretic acid increases glutamate uptake in vitro and in vivo: therapeutic implications for amyotrophic lateral sclerosis. Exp Neurol. 2008;213:229-237.

136. Shibata N, Kawaguchi-Niida M, Yamamoto T, Toi S, Hirano A, Kobayashi M. Effects of the PPARgamma activator pioglitazone on p38 MAP kinase and IkappaBalpha in the spinal cord of a transgenic mouse model of amyotrophic lateral sclerosis. Neuropathology. 2008;28:387-398.

137. Schütz B, Reimann J, Dumitrescu-Ozimek L, et al. The oral antidiabetic pioglitazone protects from neurodegeneration and amyotrophic lateral sclerosis-like symptoms in superoxide dismutase-G93A transgenic mice. J Neurosci. 2005;25:7805-7812.

138. Kiaei M, Kipiani K, Chen J, Calingasan NY, Beal MF. Peroxisome proliferator-activated receptor-gamma agonist extends survival in transgenic mouse model of amyotrophic lateral sclerosis. Exp Neurol. 2005;191:331-336

139. Lorenzl S, Narr S, Angele B, et al. The matrix metalloproteinases inhibitor Ro 28-2653 extends survival in transgenic ALS mice. Exp Neurol. 2006;200:166-171.

140. de Paulis T. ONO-2506. Curr Opin Investig Drugs. 2003;4:863-867.

141. Chuang DM, Chen RW, Chalecka-Franaszek E, et al. Neuroprotective effects of lithium in cultured cells and animal models of diseases. Bipolar Disord. 2002;4:129-136.

142. Pasquali L, Longone P, Isidoro C, Ruggieri S, Paparelli A, Fornai F. Autophagy, lithium, and amyotrophic lateral sclerosis. Muscle Nerve. 2009;40:173-194.

143. Fornai F, Longone P, Cafaro L, et al. Lithium delays progression of amyotrophic lateral sclerosis. Proc Natl Acad Sci USA. 2008;105:2052-2207.

144. Del Signore SJ, Amante DJ, Kim J, Stack EC, et al. Combined riluzole and sodium phenylbutyrate therapy in transgenic amyotrophic lateral sclerosis mice. Amyotroph Lateral Scler. 2009;10:85-94.

145. Ryu H, Smith K, Camelo SI, et al. Sodium phenylbutyrate prolongs survival and regulates expression of anti-apoptotic genes in transgenic amyotrophic lateral sclerosis mice. J Neurochem. 2005;93:1087-1098.

Neuropsychiatric Disease and Treatment

\section{Publish your work in this journal}

Neuropsychiatric Disease and Treatment is an international, peerreviewed journal of clinical therapeutics and pharmacology focusing on concise rapid reporting of clinical or pre-clinical studies on a range of neuropsychiatric and neurological disorders. This journal is indexed on PubMed Central, the 'PsycINFO' database and CAS, and is the official
146. Cudkowicz ME, Andres PL, Macdonald SA, et al. Phase 2 study of sodium phenylbutyrate in ALS. Amyotroph Lateral Scler. 2009;10:99-106.

147. Göttlicher M, Minucci S, Zhu P, et al. Valproic acid defines a novel class of HDAC inhibitors inducing differentiation of transformed cells. EMBO J. 2001;20:6969-6978.

148. Nilsson M, Hansson E, Ronnback L. Interactions between valproate, glutamate, aspartate, and GABA with respect to uptake in astroglial primary cultures. Neurochem Res. 1992;17:327-332.

149. Sugai F, Yamamoto Y, Miyaguchi K, et al. Benefit of valproic acid in suppressing disease progression of ALS model mice. Eur J Neurosci. 2004;20:3179-3183.

150. Feng HL, Leng Y, Ma CH, Zhang J, Ren M, Chuang DM. Combined lithium and valproate treatment delays disease onset, reduces neurological deficits and prolongs survival in an amyotrophic lateral sclerosis mouse model. Neuroscience. 2008;155:567-572.

151. Rouaux C, Panteleeva I, René F, et al. Sodium valproate exerts neuroprotective effects in vivo through CREB-binding protein-dependent mechanisms but does not improve survival in an amyotrophic lateral sclerosis mouse model. J Neurosci. 2007;27:5535-5545.

152. Crochemore C, Virgili M, Bonamassa B, et al. Long-term dietary administration of valproic acid does not affect, while retinoic acid decreases, the lifespan of G93A mice, a model for amyotrophic lateral sclerosis. Muscle Nerve. 2009;39:548-552.

153. Piepers S, Veldink JH, De Jong SW, et al. Randomized sequential trial of valproic acid in amyotrophic lateral sclerosis. Ann Neurol. 2009;66:227-234.

154. Corcoran LJ, Mitchison TJ, Liu Q. A novel action of histone deacetylase inhibitors in a protein aggresome disease model. Curr Biol. 2004; $14: 488-492$.

155. Kalmar B, Novoselov S, Gray A, Cheetham ME, Margulis B, Greensmith L. Late stage treatment with arimoclomol delays disease progression and prevents protein aggregation in the SOD1 mouse model of ALS. J Neurochem. 2008;107:339-350.

156. Kieran D, Kalmar B, Dick JR, Riddoch-Contreras J, Burnstock G, Greensmith L. Treatment with arimoclomol, a coinducer of heat shock proteins, delays disease progression in ALS mice. Nat Med. 2004; 10:402-405.

157. Cudkowicz ME, Shefner JM, Simpson E, et al. Arimoclomol at dosages up to $300 \mathrm{mg} /$ day is well tolerated and safe in amyotrophic lateral sclerosis. Muscle Nerve. 2008;38:837-844.

158. Brooks BR. Managing amyotrophic lateral sclerosis: slowing disease progression and improving patient quality of life. Ann Neurol. 2009;65(Suppl 1):S17-S23.

159. Scott S, Kranz JE, Cole J, et al. Design, power, and interpretation of studies in the standard murine model of ALS. Amyotroph Lateral Scler. 2008;9(1):4-15.

160. Garbuzova-Davis S, Saporta S, et al. Evidence of compromised bloodspinal cord barrier in early and late symptomatic SOD1 mice modeling ALS. PLoS One. 2007;2(11):e1205.

161. Henkel JS, Beers DR, Wen S, Bowser R, Appel SH. Decreased mRNA expression of tight junction proteins in lumbar spinal cords of patients with ALS. Neurology. 2009;72(18):1614-1616.

162. Beghi E, Mennini T, Bendotti C, et al. The heterogeneity of amyotrophic lateral sclerosis: a possible explanation of treatment failure. Curr Med Chem. 2007;14:3185-3200.

163. Clinical Trials. ALS studies. 2009. Available from: http://www clinicaltrials.gov/ct2/results?term=als. Accessed on October 10, 2009.

\section{Dovepress}

journal of The International Neuropsychiatric Association (INA). The manuscript management system is completely online and includes a very quick and fair peer-review system, which is all easy to use. Visi http://www.dovepress.com/testimonials.php to read real quotes from published authors. 